\title{
Rough vaccines in animal brucellosis: Structural and genetic basis and present status
}

\author{
Ignacio MORIYÓNa*, María Jesús GRILLÓb ${ }^{\mathrm{b}}$, Daniel MONREAL ${ }^{\mathrm{a}}$, \\ David GONZÁLEZ ${ }^{\mathrm{a}}$, Clara MARÍN ${ }^{\mathrm{b}}$, Ignacio LÓPEZ-GOÑI ${ }^{\mathrm{b}}$, \\ Raúl C. MAINAR-JAIME ${ }^{\mathrm{c}}$, Edgardo MORENO ${ }^{\mathrm{d}}$, José María BLASCO ${ }^{\mathrm{b}}$ \\ a Departamento de Microbiología, Universidad de Navarra, Aptdo. 177, 31080 Pamplona, Spain \\ ${ }^{\mathrm{b}}$ Unidad de Sanidad Animal SIA/DGA. Aptdo. 727, 50080 Zaragoza, Spain \\ ${ }^{c}$ Dpto. of Veterinary Microbiology, WCVM, University of Saskatchewan, 52 Campus Drive, \\ Saskatoon, SK, S7N 5B4, Canada \\ d Programa de Investigación en Enfermedades Tropicales (PIET), Escuela de Medicina Veterinaria, \\ Universidad Nacional, Aptdo 304-3000 Heredia, Costa Rica
}

(Received 13 March 2003, accepted 4 July 2003)

\begin{abstract}
Brucellosis control and eradication requires serological tests and vaccines. Effective classical vaccines (S19 in cattle and Rev 1 in small ruminants), however, induce antibodies to the O-polysaccharide of the lipopolysaccharide which may be difficult to distinguish from those resulting from infection and may thus complicate diagnosis. Rough attenuated mutants lack the O-polysaccharide and would solve this problem if eliciting protective immunity; the empirically obtained rough mutants 45/20 and RB51 have been used as vaccines. Strain 45/20 is reportedly unstable and it is not presently used. RB51 is increasingly used instead of S19 in some countries but it is rifampicin resistant and its effectiveness is controversial. Some controlled experiments have found good or absolute protection in adult cattle vaccinated orally (full dose) or subcutaneously (reduced dose) and in one field experiment, RB51 was reported to afford absolute protection to calves and to perform better than S19. Controlled experiments in calves, however, have shown reduced doses of RB51 to be ineffective, full doses only partially effective, and RB51 less effective than S19 against severe challenges. Moreover, other observations suggest that RB51 is ineffective when prevalence is high. RB51 is not useful in sheep and evidence in goats is preliminary and contradictory. Rough mutants obtained by molecular biology methods on the knowledge of the genetics and structure of Brucella lipopolysaccharide may offer alternatives. The B. abortus $m a n B_{c o r e}(r f b K)$ mutant seems promising in cattle, and analyses in mice suggest that mutations affecting only the O-polysaccharide result in better vaccines than those affecting both core and O-polysaccharide. Possible uses of rough vaccines also include boosting immunity by revaccination but solid evidence on its effectiveness, safety and practicality is not available.
\end{abstract}

Brucella / brucellosis / vaccines / lipopolysaccharide / genetics

Table of contents

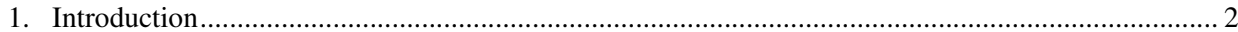

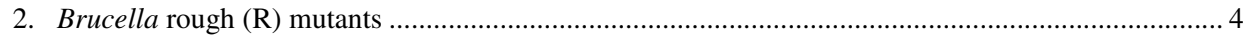

3. Structure, biosynthesis and genetics of Brucella S-LPS .......................................................... 5

* Corresponding author: imoriyon@unav.es 


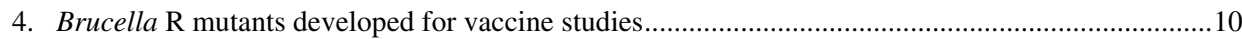

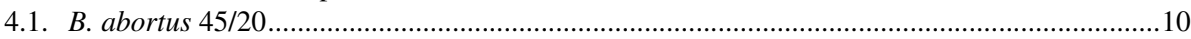

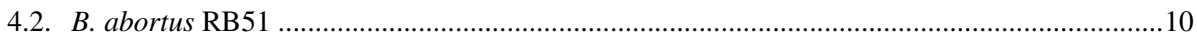

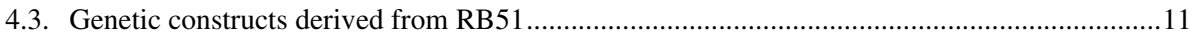

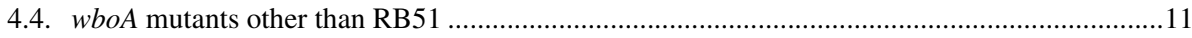

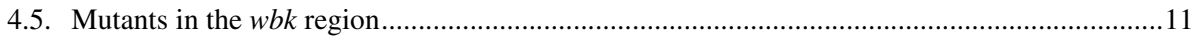

4.6. Mutants in genes affecting the LPS core structure …….................................................11

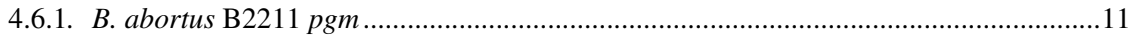

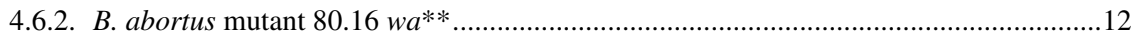

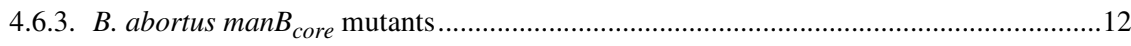

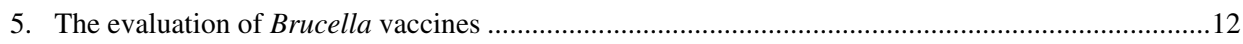

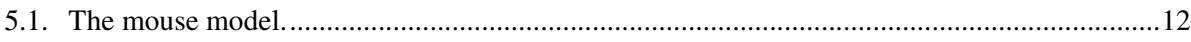

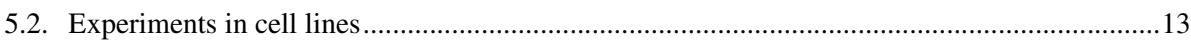

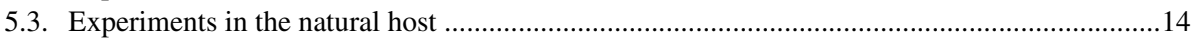

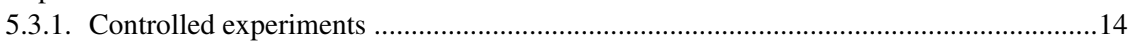

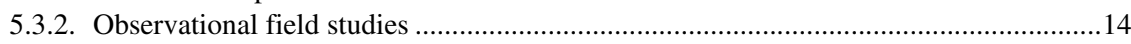

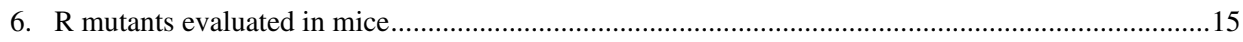

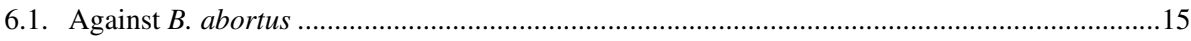

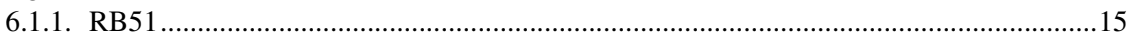

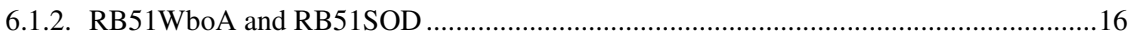

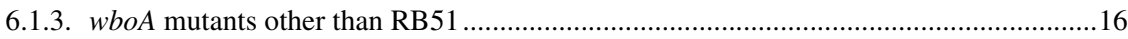

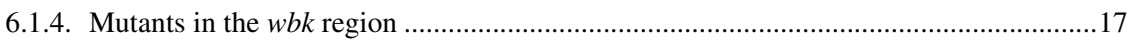

6.1.5. Mutants in genes affecting the LPS core structure ....................................................18

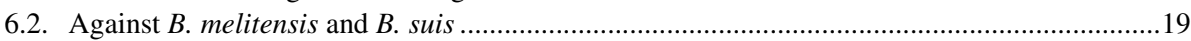

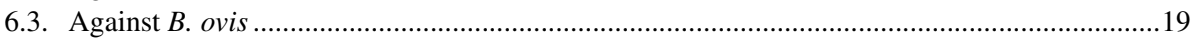

7. $\mathrm{R}$ vaccines tested in cattle

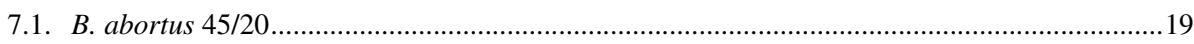

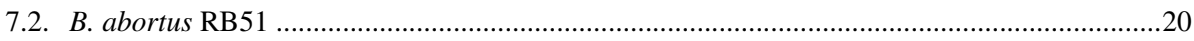

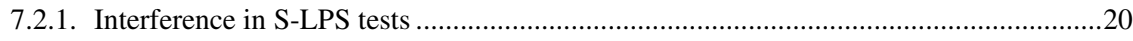

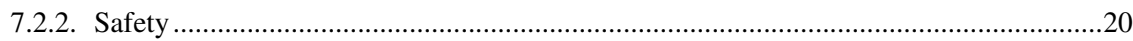

7.2.3. Protection against B. abortus in controlled experiments ...............................................21

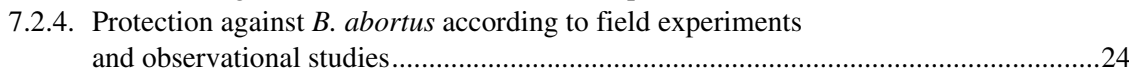

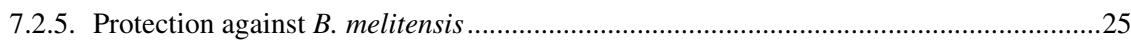

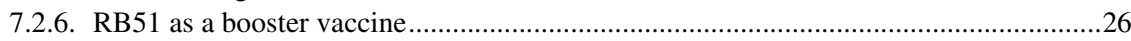

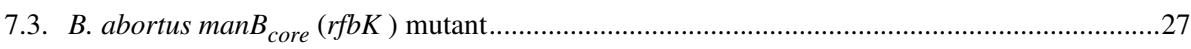

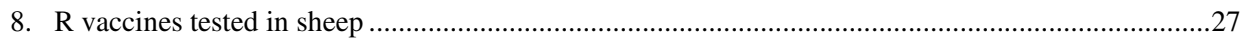

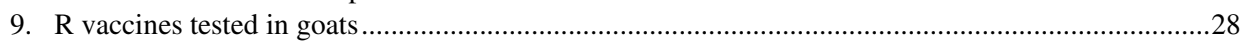

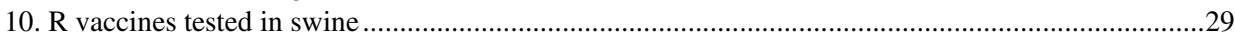

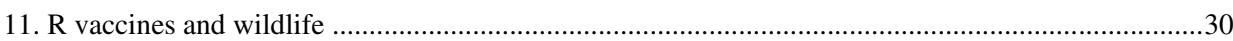

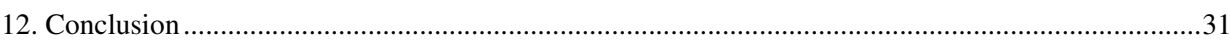

\section{INTRODUCTION}

Brucella is an $\alpha$ Proteobacteria causing an infectious disease of mammals that is transmitted to humans. Ruminants and swine are heavily infected in many areas of the world, and wildlife is not exempt of brucellosis, thus acting as a potential reservoir for domestic livestock and a potential risk for humans. Brucella species differ in their hosts' preference, physiological abilities and cell surface structural characteristics. 
Those affecting domestic livestock are B. melitensis (sheep and goats), B. abortus (cattle), B. suis (swine), and B. ovis (sheep). Because domestic ruminants and swine are essential to the economy of millions of persons, particularly in low income countries, brucellosis is a major cause of direct economical losses and a major impediment for trade and exportations. Moreover, human brucellosis is a severe and debilitating disease requiring a prolonged antibiotic treatment and often leaving permanent and disabling sequelae [13]. Thus, its eradication is a major goal of public health programs in affected countries.

It is generally agreed that under most conditions, vaccination is essential for the control of bovine, ovine and caprine brucellosis. Controlled experiments and accumulated knowledge have demonstrated that the B. abortus strain 19 (S19) in cattle and B. melitensis strain Rev 1 in sheep and goats are useful vaccines [7, 17, 84]. However, both have some undesirable traits: they are infectious for humans [7, 77], may be abortifacient when used in pregnant animals (S19 is also of limited use in males) [17, 84], and induce an immune response that may be difficult to distinguish from that resulting from infection, particularly when adult animals are vaccinated [17, 71, 84, 123]. This is troublesome because, depending on the challenge, no absolute protection is achieved with these vaccines and, therefore, serological tests do not always elucidate whether a given animal is infected or simply shows postvaccinal antibodies. Rev 1 shows some additional negative traits: it is resistant to streptomycin, one of the antibiotics of choice used to treat brucellosis in combination with tetracyclines [13], and it is relatively unstable thus requiring careful standardization to prevent variations in safety and effectiveness $[10,17,18,52]$. The rate of abortion caused by S19 is low (less than $1 \%$ in a large study involving over 10000 cows which were 7 to 8 months pregnant [84]) but that of Rev 1 can be higher, particularly in association with some of its variants [17].
The interference in the serological diagnosis has to be understood in the context of the goal to be achieved by vaccination. Individual identification, strict control of animal movements and trade, and 100\% vaccine coverage and monitoring of the serological and clinical status are the most relevant requisites to achieve eradication. In nearly all cases, this also implies to have the means to face the costs of slaughtering infected or suspicious animals. When prevalence is high or these requirements are not met (e.g. in low-income countries), the relevant point is to use the best vaccine in terms of protection and the interference in serological tests is not a significant problem since the only realistic goal should be to control the disease and to reduce the economical losses and human contagion until prevalence is diminished. This consideration also applies to revaccination. Indeed, revaccination with the classical vaccines aggravates the problem of the interference in the serological tests but the duration of the immunity provided by these vaccines is not known with certainty. At least for S19, it seems to last for several pregnancies but it is believed that revaccination increases immunity [84] and some experiments have shown that the best protection is obtained by subcutaneous vaccination of calves with S19 followed by a conjunctivally administered booster dose [43]. Revaccination may be necessary to control the disease in large herds, or when the test and slaughter programs are not economically viable, as in many low-income areas, because it reduces the rate of abortions and the bacterial excretion and transmission in infected flocks [84].

When eradication is the goal of a brucellosis program, several strategies to lessen the interference of S19 and Rev 1 vaccination in the serodiagnosis have been proposed. They include the following: (i), to limit vaccination to young animals; (ii), to use a reduced dose of the vaccine in adults; and (iii), to vaccinate by the conjunctival route (rather than subcutaneously) (for discussions on the value of these different 
alternatives, see references $[17,56,84$, 100]). These strategies are usually complemented with diagnostic tests that are highly specific to discriminate between vaccinated and infected animals $[17,33,34,36,63,67$, $71,72,84,85]$. Combinations of these strategies have been useful in countries with efficient veterinarian services and relatively small and well controlled herds but they may be difficult to apply to large herds or when extensive breeding and transhumance systems exist. Vaccines devoid of diagnostically significant antigens combined with diagnostic tests that use such antigens represent an alternative $[1,20,38$, 113]. The relevant diagnostic antigen in B. abortus and B. melitensis infections is the smooth (S) lipopolysaccharide (LPS) present in field strains as well as in S19 and Rev 1. Indeed, it is the S-LPS in these vaccines that complicates the diagnosis. As in other S gram-negative bacteria, this molecule has three sections: the O-polysaccharide (O-PS), core oligosaccharide and lipid A. The O-PS is the immunodominant section to which the majority of antibodies resulting from either infection or S19 and Rev 1 vaccination are directed $[4,85]$.

\section{BRUCELLA ROUGH (R) MUTANTS}

Brucellae devoid of the O-PS are termed rough or "R" because their colonial surface contrasts with the glistening, smooth aspect of those carrying S-LPS. They can naturally be members of the $\mathrm{R}$ Brucella species (B. canis and B. ovis) or mutants derived from the $\mathrm{S}$ Brucella species (B. melitensis, B. abortus and B. suis). Cultures of S brucellae spontaneously dissociate to generate mixtures of $\mathrm{S}$ and $\mathrm{R}$ colonies, the latter formed by $\mathrm{R}$ mutants [9]. Owing to their lack of antigenic O-PS, true R mutants neither induce anti O-PS antibodies nor react with antibodies of this specificity. They also show other outer membrane topological and physiological changes associated with the lack of O-PS. Manifestations of these changes are the uptake of crystal violet, the autoagglutination in acryflavin solutions and the sensitivity to Brucella phages specific for the $\mathrm{R}$ species [9]. Since the $\mathrm{S} \rightarrow$ $\mathrm{R}$ dissociation occurs spontaneously with a frequency that depends on the strain and growth conditions, repeated in vivo or in vitro passage has been used to obtain $\mathrm{R}$ vaccines. The $B$. abortus $45 / 20$ and RB51 strains were developed in this way [75, 112]. Alternatively, R mutants can be generated by Molecular Genetics methods such as transposon mutagenesis or deletion of genes involved in S-LPS biosynthesis [3, $50,51,76,78,126,135]$.

It has been known for a long time that spontaneous Brucella R mutants are attenuated [116]. This attenuation has been ascribed to the increase in both the antibodyindependent complement activation [3,27, 44] and the sensitivity to polycationic bactericidal peptides $[3,47,74,105]$. In addition, $\mathrm{R}$ mutants display altered attachment to cells $[32,48,115]$. Moreover, since the $\mathrm{S}$ brucellae are intracellular parasites able to alter the constitutive intracellular trafficking (i.e. the one followed by inert particles or non-virulent Brucella) [99], other factors related to the interplay of $\mathrm{R}$ mutanthost cells must be important, an aspect that has not been investigated so far. $\mathrm{R}$ mutants have altered outer membrane topology and LPS acylation patterns [78] and both features could be relevant in this regard.

Live vaccines induce the appropriate immunity against Brucella $[7,62,138]$ and, therefore, $\mathrm{R}$ mutants are potential brucellosis vaccines. Clearly, their advantage as vaccines is that they should cause no interference in most serodiagnostic tests (but see Sect. 7.2.1). On the contrary, they have several potential drawbacks: (i), if infectious for humans or other animal species, $\mathrm{R}$ vaccine infections would be unnoticed in standard serological tests (that detect antiO-PS antibodies); (ii), despite the extended opinion that antibodies do not play a role in ruminant Brucella infections, there is a paucity of clear-cut experimental data on this 
point and anti-O-PS antibodies may be important in protecting animals against $\mathrm{S}$ brucellae; and (iii), $\mathrm{R}$ mutants may be overattenuated and their rapid clearance from the animals may result in an insufficient antigenic stimulus. In addition, $\mathrm{R}$ mutants may not be equally efficient in all animal species affected by smooth $\mathrm{Bru}$ cella. Point (i) could be approached by using anti-core or anti-protein serological tests, PCR protocols specifically designed for the particular R mutant, or bacteriological culture followed by typing. On the contrary, point (ii) is critical and the problem it poses is intrinsic to the $R$ vaccine approach (see Sect. 5.1). With regard to point (iii), it cannot be assumed in the present state of knowledge that all $\mathrm{R}$ mutations (and $\mathrm{R}$ mutants) result in attenuation in the natural host or, if so, that they are all equivalent in this aspect. Both the results of comparative studies [130] and the existence of the Brucella $\mathrm{R}$ species virulent for their hosts (B. canis in dogs and B. ovis in sheep) show that not only the O-PS but also the LPS core is implicated in Brucella virulence. Thus, different core deficiencies may result in different degrees of attenuation and, therefore, the structure, biosynthesis and genetics of Brucella S-LPS has to be taken into account to design the best possible $\mathrm{R}$ vaccine candidates. This aspect is developed below.

\section{STRUCTURE, BIOSYNTHESIS AND GENETICS OF BRUCELLA S-LPS}

The structure of the Brucella S-LPS is known in part. According to nuclear magnetic resonance studies, the O-PS is a homopolymer of $\mathrm{N}$-formyl-perosamine either exclusively in $\alpha(1-2)$ linkages (for example in $B$. abortus biotype 1 ) or in $\alpha$ (1-2) plus $\alpha$ (1-3) in $\mathrm{a} \geq 4: 1$ proportion (4:1 in B. melitensis biotype 1) [97]. These O-PS carry three basic types of overlapping epitopes: $\mathrm{C}$ (common to all chemical types of Brucella O-PS), $\mathrm{M}$ (present in those O-PS with $\alpha$ (1-3) linkages) and A (present in those O-PS with no $\alpha$ (1-3) linkages or with a proportion of $\alpha(1-2)$ to $\alpha$ (1-3) linkages higher than 4:1). Nuclear magnetic resonance studies also show that the S-LPS of Yersinia enterocolitica 0:9 carries a homopolymer of $\mathrm{N}$-formyl-perosamine in $\alpha$ (1-2) linkages and, accordingly, it should be identical to O-PS such as those of the B. abortus biotype 1 [97]. It might be, however, that some aspect of these structures has escaped the nuclear magnetic resonance analyses because, whereas some monoclonal antibodies of O-PS specificity react equally with S Brucella and $Y$. enterocolitica O:9 (Cyb epitopes), others recognize epitopes common to all S Brucella but not to $Y$. enterocolitica $\mathrm{O}: 9$ (Cb epitopes) [24, 37], strongly suggesting subtle structural differences. The structure of the Brucella LPS core is largely unknown and qualitative studies show 3-deoxy-D-manno-2octulosonic acid, mannose, glucose, glucosamine and quinovosamine as the main sugars (reviewed in references [82, 130]). That of lipid A has been partially elucidated [103, 130].

The synthesis of LPS in Brucella is largely unknown but the genetic evidence available $[31,51,96]$ is fully consistent with a mechanism similar to that existing in some of the best studied gram-negative bacteria [54, 64, 104]. First, lipid A is synthesized on the inner face of the cytoplasmic membrane. Second, through the sequential action of glycosyltransferases, sugars are added to lipid A until the core oligosaccharide is completed. These two pathways are intermingled since two 3-deoxy-D-manno2-octulosonate residues are added before lipid A synthesis is finished. On the contrary, the O-PS is synthesized in an independent pathway and, once its biosynthesis is carried through, it is linked to the acceptor sugar of the completed lipid A-core. Depending on the particular O-PS, there are three known types of mechanisms of synthesis, and that of Brucella belongs to the so-called $\mathrm{ABC}$ transporter-dependent (or wzy-independent) type [51, 64]. In this pathway (Fig. 1), a lipid carrier (undecaprenol 


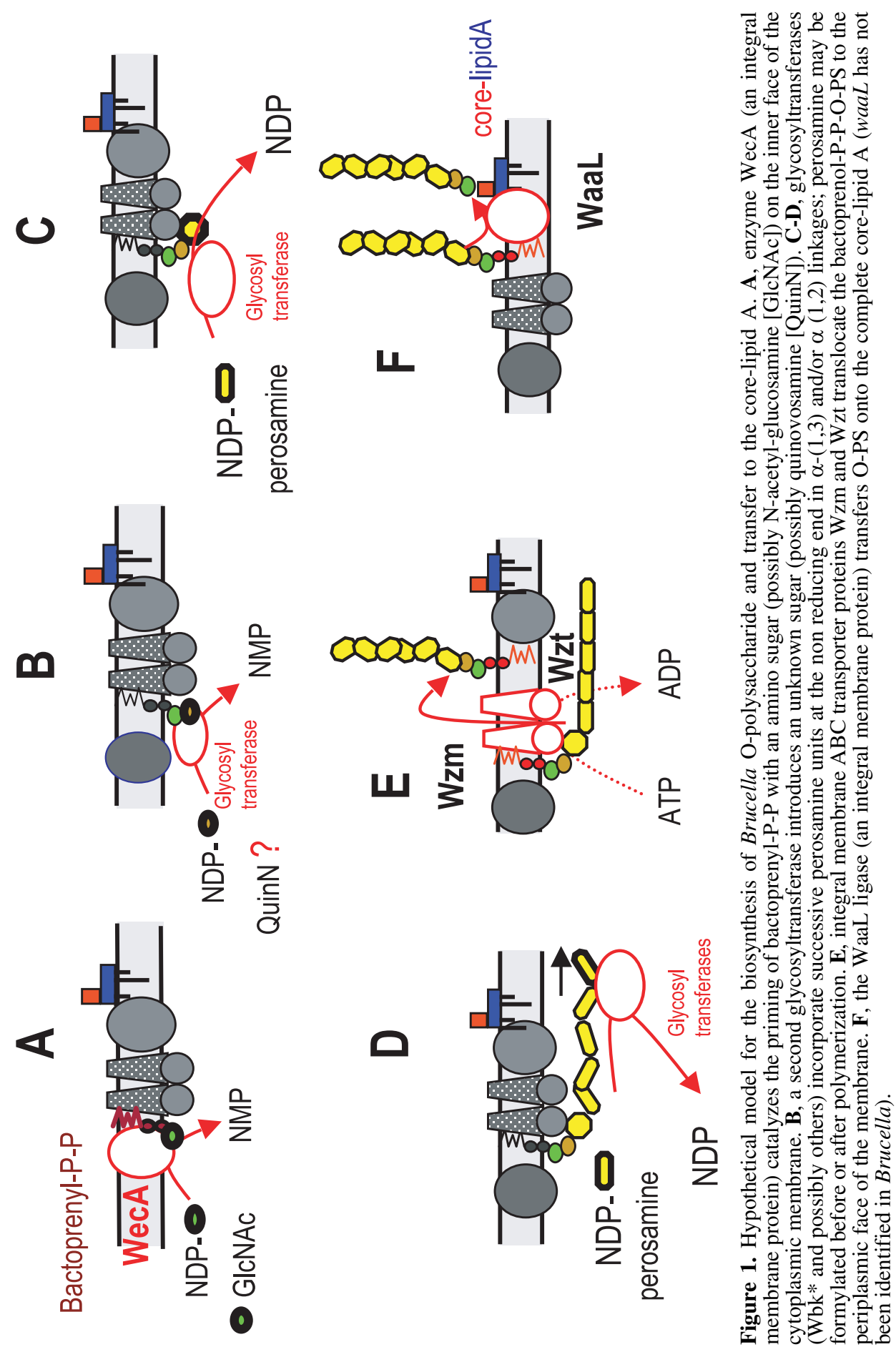


pyrophosphate) on the cytoplasmic side of the membrane is first primed with an amino sugar by the WecA protein. Then, O-PS sugar units are inserted successively at the non-reducing end (i.e. the "tip" of the growing polysaccharide) by glycosyltransferases. Finally, the $\mathrm{ABC}$ proteins translocate the amino sugar-O-PS (possibly still linked to the undecaprenol) to the periplasmic side of the membrane where a ligase (WaaL) binds the amino sugar-O-PS to the completed lipid A-core. Thus, when the synthesis of the core is blocked, the O-PS is generally not incorporated to the LPS. In addition to the lipid A, core, and O-PS pathways, there are subsidiary pathways that provide the necessary nucleotide-sugar precursors. Some of them are exclusive to LPS biosynthesis whereas others are housekeeping pathways.

The more recent nomenclature for the genes coding for the enzymes of LPS synthesis [104] uses four letters: ${ }^{1}$ (i), $l p x^{*}$ for those involved in the early steps of lipid A synthesis; (ii), $w a^{* *}$ for those involved in the late steps of lipid A synthesis, in core synthesis and in the ligation of the amino sugar-O-PS to the lipid A-core (waaL); (iii), $w b^{* *}$ for those involved in the OP-S synthesis; and (iv), $w z^{* *}$ for those involved in OP-S processing (for example, $w z m / w z t$ are the genes coding for the $\mathrm{ABC}$ transporters such as those acting on Brucella OP-S). The genes coding for the enzymes belonging to the precursor pathways follow a conventional nomenclature (for example man* for mannose biosynthesis, per for perosamine synthetase, etc.) even though they functionally belong to LPS pathways. Sometimes there are two different genes for the same enzymatic function as there can be two pathways for the same sugar when it is present in both the core or the O-PS and, in this case, subindexes are used (for example, $m a n B_{\text {core }}$ and $m a n B_{\mathrm{OAg}}$ for the phosphomannomutases of core and O-PS [O Anti-

\footnotetext{
${ }^{1}$ In what follows, asterisks represent any letter, and the last one is capitalized.
}

gen] mannose synthesis). At least sixteen genes have been proven to be involved in Brucella LPS synthesis by analysis of the corresponding mutants (Tab. I) and, as in many bacteria, most of the O-PS ones are clustered in a region (the Brucella wbk region; Fig. 2). Although mutations in some genes outside $w b k$ also bring about an $\mathrm{R}$ phenotype, their assignation to the core or O-PS pathways is less clear (Tab. I). As judged by the analyses derived from the complete sequence of the B. melitensis and B. suis genomes [31, 96], Brucella LPS genes are scattered in both chromosomes with the exception of the $w b k$ region (Tab. I).

From the above-summarized data, it follows that B. melitensis, B. abortus and $B$. suis $\mathrm{R}$ strains should result from mutations in some $w a^{* *}$ genes (including $w a a L)$, in all $w b^{* *}$ genes, in the $w z m / w z t$ genes, and in genes of the pathways that lead to precursors of core and O-PS sugars (for example $m a n B_{\text {core }}$ and per, respectively). But for the absence of an O-PS linked to the remaining LPS molecule, it can be predicted that not all these mutants are equivalent and they can be hypothetically grouped as follows: (i), R mutants that have a complete lipid A-core plus a cytoplasmic O-PS, the incorporation of which to the LPS is blocked (at least the $w z m / w z t$ and possibly the waaL mutants); (ii), $\mathrm{R}$ mutants that have a complete lipid A-core but no O-PS (mutants in $w b^{* *}$ glycosyltransferases, in wecA, and in genes coding for enzymes necessary for the synthesis of some precursors, such as $m a n B_{\mathrm{OAg}}$, gmd and per) and (iii), $\mathrm{R}$ mutants that have progressive deficiencies in the core and that may or may not accumulate cytoplasmic O-PS (mutants in some $w a^{* *}$ genes and in some precursor genes such as $\operatorname{man} B_{\text {core }}$ ). Mutants of each of these three groups have in fact been described [50, 51, 76, 78, 126], and the question then arises as to what extent they are equivalent in attenuation and immunizing abilities. 
I. Moriyón et al.

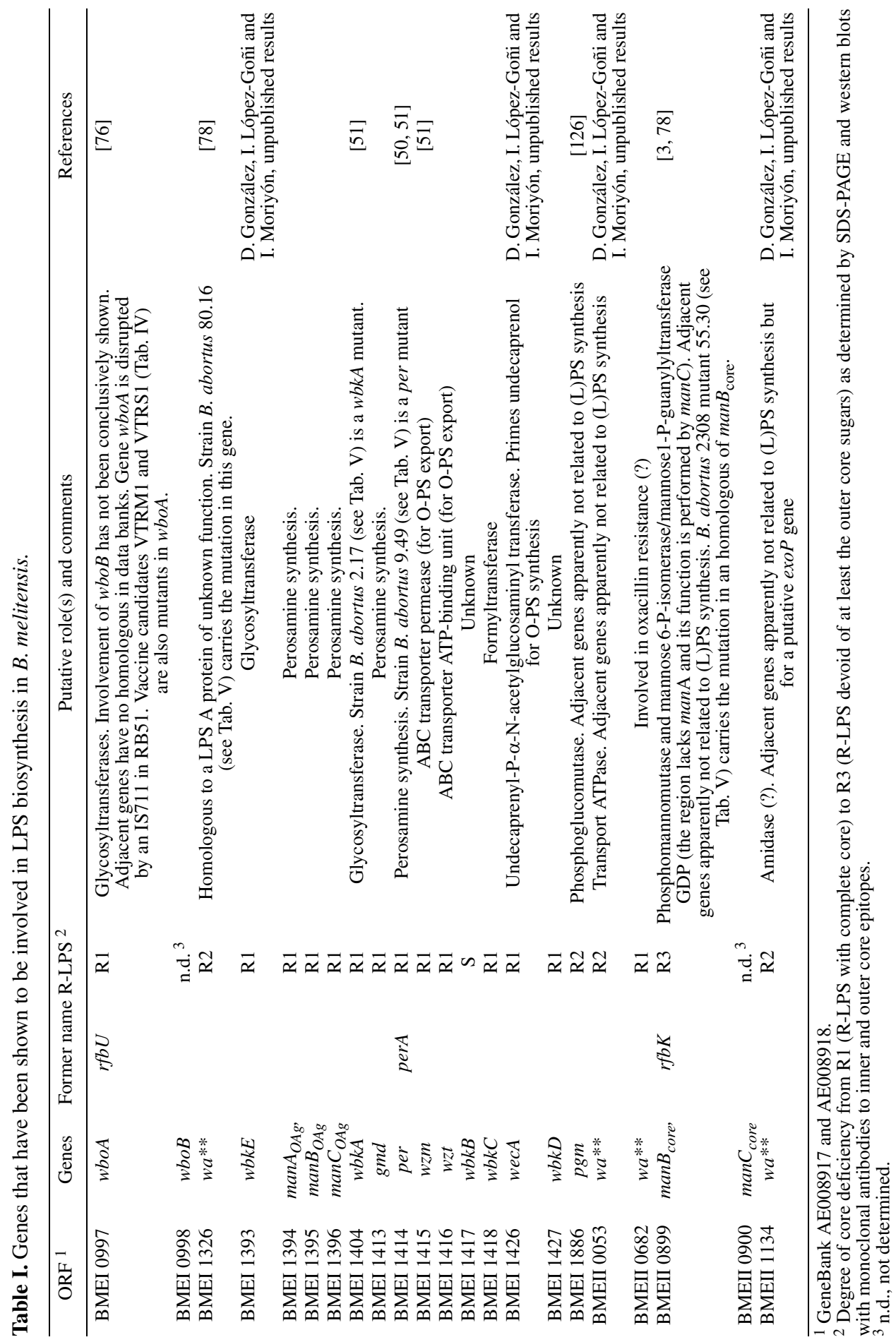



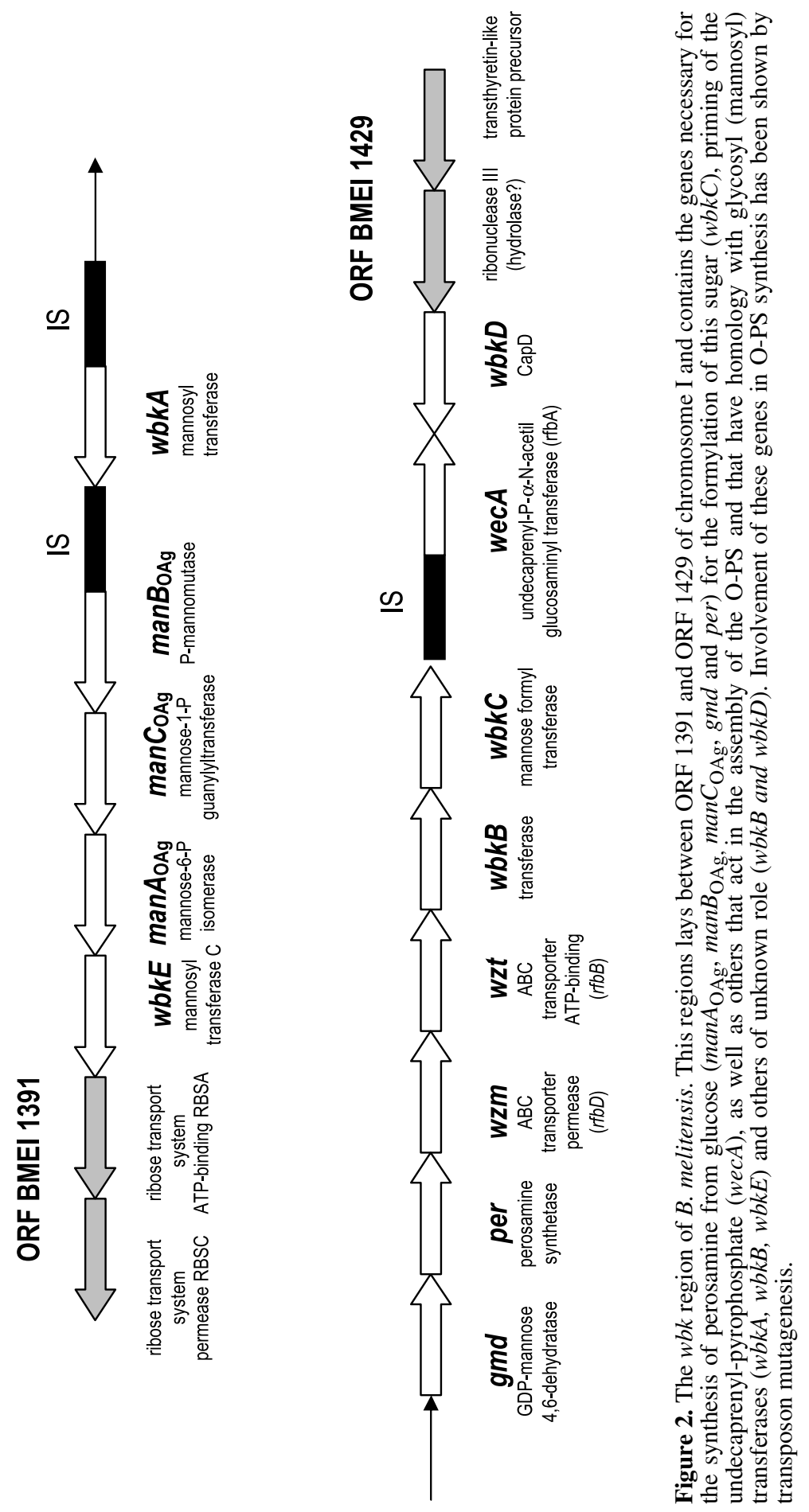
The above picture is complicated by the fact that S brucellae carry a second surface polysaccharide (the native hapten) akin to the O-PS with which it shares the sugar backbone [12] but from which it differs in the degree of formylation (50-60\% instead of over $90 \%$ for the O-PS) (M. Staaf, G. Widmalm, A. Weintraub, A. Cloeckaert, A.P. Teixeira-Gomes, R. Díaz, E. Moreno, and I. Moriyón, unpublished results). The defects in perosamine synthesis prevent the synthesis of this polysaccharide but presently it is not known or can be predicted how defects in later steps may affect its location and expression.

\section{BRUCELLA R MUTANTS DEVELOPED FOR VACCINE STUDIES}

\subsection{B. abortus $45 / 20$}

This $\mathrm{R}$ vaccine was obtained after twenty passages in guinea pigs of a field isolate (B. abortus strain 45) in 1938. However, the original $45 / 20$ strain was reported to revert to $S$ pathogenic forms when injected into cattle [28, 84, 125]. Alton [5] reports of experiments with several 45/20 stocks which, after repeated passages in guinea pigs, showed either S-intermediate and $\mathrm{R}$ colonies or only $\mathrm{R}$ forms depending on the origin of the stocks. This suggests that the original strain contained in fact several different clones so that the S-intermediate ones became selected when injected into cattle. Also, it seems likely that different laboratory variants of this strain have coexisted for years. A 45/20 stock maintained in the laboratory of the authors since 1982 and originally obtained from G. Dubray (Institut National de la Recherche Agronomique, Tours, France) is stable but it produces small amounts of O-PS of possibly an anomalously polymerized and reduced number of sugar units ([48], and E. Moreno and I. Moriyón, unpublished results). The genetic defects in this strain are unknown and the vaccine is not presently marketed.

\subsection{B. abortus RB51}

Strain RB51 is a spontaneous R mutant selected after repeated in vitro passages of B. abortus 2308 (United States Department of Agriculture challenge strain) on media containing rifampin and penicillin [112]. Selection was performed using the crystal violet and acryflavin tests. RB51 carries an IS711 spontaneously inserted into wboA (putatively coding for a glycosyltransferase) [131]. However, a $w b o A$ transposon mutant obtained from strain 2308 is not as attenuated as RB51 [76] and the protection afforded by wboA mutant vaccines in mice is better than that provided by RB51 (see Sect. 6.1.3), which shows that RB51 carries additional and unknown defects. In the complete sequence of $B$. melitensis, $B$. suis and $B$. abortus genomes (an annotated B. abortus complete sequence is not available) $w b o A$ maps outside of the main $w b k^{*}$ O-PS genetic region (Tab. I). RB51 accumulates small amounts of O-PS [25]. This is noteworthy because, accepting that the current model of the B. abortus LPS structure is correct, mutation in a $w b^{* *}$ gene should prevent O-PS synthesis. Complementation of RB51 with wboA increases $\mathrm{O}$-chain expression but does not restore the S phenotype [132] suggesting that other LPS genes are affected. In addition, although sodium dodecyl sulfate (SDS) polyacrylamide gel electrophoresis (SDS-PAGE) migration patterns have been interpreted to mean that RB51 carries a LPS with a complete core, chemical analyses show that this R-LPS contains 2.5 times less mannose than the B. abortus RA1 wboA mutant [76]. The presence in RB51 of additional mutations in genes not involved in LPS synthesis cannot be excluded either.

On the contrary to $45 / 20$, RB51 is stable [112] and it is currently being used in some countries instead of S19. Although it should show very low or no virulence in humans, there is little information on this point and there has been at least one case of RB51 infection in a veterinarian demonstrated by bacteriological isolation and typing of the 
strain [134]. It has to be stressed that RB51 is resistant to rifampin, an antibiotic currently used in the groups of brucellosis patients that cannot be treated with streptomycin (pregnant women, children of young age, and endocarditis and neurobrucellosis cases) [13].

\subsection{Genetic constructs derived from RB51}

RB51 has been used as the starting strain in two genetic manipulations. First, the $w b o A$ defect has been complemented with a functional $w b o A$ gene to generate strain RB51Wboa [132]. This strain keeps the $\mathrm{R}$ phenotype manifested in the crystal violet and acryflavin tests, but expresses increased amounts of O-PS which by immunoelectronmicroscopy seems to accumulate in the cytoplasm. However, at least part of this O-PS may be linked to a lipid to give an immunogenic form because it migrates in SDS-PAGE and vaccination of mice with RB51WboA elicits IgG antibodies of at least $\mathrm{C}$ specificity. Second, the Brucella $\mathrm{Cu} / \mathrm{Zn}$ superoxide dismutase gene has been introduced in RB51 to obtain strain RB51SOD which overexpresses (tenfold) this protein [133]. The aim of this manipulation is to increase the expression of a Brucella antigen and a possible virulence factor on the RB51 background.

\section{4. wboA mutants other than RB51}

Mutants in this putative glycosyltransferase gene (Tab. I) have been obtained from B. melitensis $16 \mathrm{M}$ and B. suis 2579 by allelic exchange to generate the strains VTRM1 and VTRS1, respectively. Both are kanamycin resistant since they carry a Tn5 element [135]. Although, it was originally named $r f b U$, blast analysis of the Salmonella typhi $\mathrm{RfbU}$ prototype against the B. melitensis genome shows the highest similarity (E value $1 \mathrm{e}^{-16}$ ) with WbkA (see Tab. I), and more recently the gene has been renamed $w b o A$ [113] (E value for RfbU ver- sus WboA is only $2 \mathrm{e}^{-04}$ ). The VTRM1 and VTRS1 mutants are stable in mice, lack reactivity with monoclonal antibodies of $\mathrm{C}$ specificity and have an $\mathrm{R}$ phenotype but they have not been tested for the absence of core defects or expression of cytoplasmic O-PS.

\subsection{Mutants in the $w b k$ region}

Several mutants in this cluster of Opolysaccharide genes have been described $[50,51,78]$, and two have been analyzed as vaccines. B. abortus 2.17 and $B$. abortus 9.49 have been obtained from $B$. abortus 2308 by transposon mutagenesis and selection for polymyxin B sensitivity, and they carry the Tn5 insert (they are kanamycin resistant) in wbkA and per, respectively [78]. Both are resistant to the S Brucella specific phages, sensitive to the R Brucella specific $\mathrm{R} / \mathrm{C}$ phage and positive in the crystal violet and acryflavin tests and do not express O-PS. As judged by the electrophoretic mobility (Tab. I) and the reactivity with monoclonal antibodies specific for the inner and outer core epitopes [107], the R-LPS of both mutants keeps an intact core oligosaccharide [78], which is consistent with the position of wbkA in the major O-PS genetic region (Fig. 2) and the putative role of Per.

\subsection{Mutants in genes affecting the LPS core structure}

\subsubsection{B. abortus B2211 pgm}

This mutant carries a gentamicin-resistance non polar cassette in the pgm (phosphoglucomutase) gene of B. abortus 2308 [126]. It is resistant to the S-Brucella specific $\mathrm{Tb}$ phage and carries R-LPS as judged by SDS-PAGE analysis. The central role of this enzyme in the synthesis of hexoses derived from glucose makes pleiotropic effects on the synthesis of oligo- and polysaccharides likely and, at least, the pgm mutant is also blocked in the synthesis 
of the periplasmic $\beta(1,2)$ cyclic glucans $[19,57]$. Mutation in the homologous gene of B. melitensis causes a core defect as judged by the electrophoretic mobility in SDS-PAGE of its R-LPS (Tab. I).

\subsubsection{B. abortus mutant $80.16 \mathrm{wa}^{* *}$}

This is a mutant in a putative glycosyltransferase gene involved in core synthesis (hence its provisional denomination as $\left.w a^{* *}\right)$ (Tab. I) as shown by SDS-PAGE and Western blots with monoclonal antibodies to core epitopes [78]. Like B. abortus 9.49, it was obtained by Tn5 transposon mutagenesis of B. abortus 2308 and selection for polymyxin B sensitivity. This mutant is resistant to kanamycin, to the $\mathrm{S}$ brucellaphages, sensitive to phage $\mathrm{R} / \mathrm{C}$ and does not express O-PS. A remarkable feature of the R-LPS of this mutant is that while keeping a fully reactive outer core epitope, it shows a reduced reactivity with monoclonal antibodies to the inner core epitope suggestive of a branch in the inner core in which the missing sugar(s) would be placed.

\subsubsection{B. abortus manB $B_{\text {core }}$ mutants}

Two different mutants in this gene, both from $B$. abortus 2308, have been described: the $r f b K$ mutant $[2,3]$ and mutant 55.30 [78]. The mutated gene (formerly $r f b K$ but manB according to recent nomenclature [104]) putatively codes for a phosphomannomutase and is thus predicted to be involved in the synthesis of mannose-1-P. Although mannose-1-P is a precursor of perosamine (the O-PS sugar), the mutated gene is not homologous to the $\operatorname{man} B$ of the wbk region ( $m a n B_{O A g}$, Fig. 2) and its location (Tab. I), the lack of reactivity with monoclonal antibodies of outer core specificity and the SDS-PAGE profile of the corresponding R-LPS (Tab. I) show that it acts as a $\operatorname{man}_{\text {core }}$ [78]. This is consistent with the presence of mannose in the core of B. abortus (see Sect. 3).

\section{THE EVALUATION OF BRUCELLA VACCINES}

\subsection{The mouse model}

Mice are relatively resistant to brucellosis and many unspecific stimuli, stress and inflammatory responses can induce some degree of resistance or increase susceptibility. Because of the high costs and long time span of the experiments in natural hosts, however, mice have been used as a preliminary step in the analyses of vaccines against brucellosis $[2,3,60,78,79,112$, 120]. Although there are variations in the protocols used by the different authors, a method has been standardized for the quality control of the classical S live anti-Brucella vaccines and it is currently accepted by the OIE and the European Union [10, 11]. The method allows the prediction of the safety and immunogenicity of Rev 1 and S19 seed stocks on the values of two complementary parameters: the residual virulence (i.e., the persistence in the spleen determined as the Recovery Time 50 $\left[\mathrm{RT}_{50}\right]$ of the vaccine) and the immunogenicity (i.e., the ability to protect against a challenge with a virulent strain determined as the number of virulent bacteria in the spleen). These parameters are measured under a tightly defined set of experimental conditions, including the number and breed of the animals, route of inoculation, doses (vaccine and challenge), challenge strain, and time intervals at which the number of colony forming units (CFU) in spleens are determined $[18,52]$. This particular mouse model discriminates both insufficiently attenuated and ineffective Rev 1 and S19 from useful seed stocks by using as controls the $\mathrm{RT}_{50}$ and immunogenicity of reference stocks of the respective vaccines known to perform satisfactorily in sheep and cattle. These ideas have been extrapolated to the evaluation of $\mathrm{R}$ vaccine candidates and it has been found that different $\mathrm{R}$ mutants show differences in splenic growth curves $[3,78]$ and immunogenicity [78]. However, the underlying assumption that, like $S$ strains, 
differences in splenic growth curves and CFU after a challenge reflect differences in virulence/attenuation and immunogenicity of $\mathrm{R}$ vaccines in the natural host has not been put to test. In addition, on the contrary to what occurs with the $\mathrm{S}$ vaccine seed stocks, there is no experience with different $R$ vaccines in the field and, therefore, there are no standards to define optimal $\mathrm{RT}_{50}$ and immunogenicity in the mouse model. A reasonable assumption is that an $\mathrm{R}$ mutant showing RT50 and immunogenicity values similar to those of the $\mathrm{S}$ vaccines should be a promising vaccine candidate for testing in the natural host. It is possible to obtain RT50 values with some R mutants similar to those of $\mathrm{S}$ vaccines by increasing the number of CFU administered (see below), but the interpretation of the immunity is not straightforward. Experience shows that protection with respect to unvaccinated controls is easily achieved in mice using killed vaccines or antigens (such as S-LPS) that have little or no efficacy in the natural hosts. Thus, when evaluating the $\mathrm{R}$ vaccine candidates, it is always important to include not only unvaccinated but also Rev 1 or S19 vaccinated mice as controls, and to compare the protection against these "gold" standards. Under these conditions, at least when the challenge is an $\mathrm{S}$ virulent $B$. abortus or $B$. melitensis strain, the immunity generated by $R$ vaccines is always lower than that observed with the $S$ vaccines $[53,78,120$, 135]. Indeed, $S$ vaccines elicit antibodies to the S-LPS but, whereas the role of cellular immunity in protection is clear, that of antiS-LPS antibodies against Brucella infection in natural hosts has been a matter of controversy for many years. Despite the extended notion that it is a proven fact that antibodies are not relevant in protection, there is a paucity of experimental data. Maternal antibodies may play a role in protecting calves born within infected herds [123] but animals vaccinated by the conjunctival route, a method eliciting a shorter and less intense antibody response, are as protected as those vaccinated subcutaneously $[17,84,100]$. On the contrary, it is clear that anti S-LPS antibodies are by themselves protective in mice $[58,80,101$, 122] mainly because, as opposed to non opsonic routes, capture by $\mathrm{Fc}$ or $\mathrm{C} 3 \mathrm{~b}$ dependent routes lead to a quick destruction of Brucella by professional phagocytes [99]. Thus, it is not known to what extent the $S$ versus $R$ vaccine comparisons in mice can be extrapolated to the natural hosts. It seems likely, however, that the model is not so biased when used to compare different $R$ vaccines.

\subsection{Experiments in cell lines}

For obvious reasons, the usefulness of cell lines and explants is limited to an evaluation of some aspects of the virulence of $\mathrm{R}$ mutants. Some $\mathrm{R}$ mutants, such as the B. suis $\operatorname{man} B_{\text {core }}$ have unpaired ability to multiply in human monocytic THP1 and HeLa cell lines [46], and the B. abortus B2211 pgm mutant is also attenuated in HeLa cells [126]. On the contrary, the B. melitensis $\mathrm{B} 3 \mathrm{~B} 2$ per mutant seems to multiply normally in an immortalized bovine macrophage cell line [50]. It is not possible to know whether these are strain or methodological differences and the observations are presently of little use in the design of $\mathrm{R}$ vaccines. However, it has been shown that $\mathrm{S} 19$ differs from virulent $B$. abortus in that, although both are detected first in early endosomes and then in autophagic vacuoles of HeLa cells, the vaccine is eventually degraded in lysosomes, whereas the virulent strain is not [98]. This suggests a characteristic pathway for, at least, one of the vaccines with proved efficacy in the natural host and opens the possibility of comparing the intracellular behavior of LPS mutants against that of virulent and reference vaccine strains as a means to eliminate both non attenuated and overattenuated vaccine candidates. Thus, future studies on the intracellular behavior of the different $R$ mutants in professional and non professional phagocytes may be of help to select vaccine candidates. 


\subsection{Experiments in the natural host}

Evaluations in the natural hosts can be performed in controlled experiments and in the field.

\subsubsection{Controlled experiments}

Controlled experiments are based on the comparison of the clinical, bacteriological and serological findings in homogeneous (breed, age sex and reproductive status) groups of randomly selected animals in numbers adequate for statistical analysis. In these experiments, it is possible to strictly control the preparation, dosage and application of the vaccine. Controls include unvaccinated animals and, ideally, animals vaccinated with the reference vaccine. The efficacy is determined after a time span that varies depending on the purpose of the experiments. The animals are usually challenged during the middle (5-6 months for cattle, and 2-3 for sheep and goats) of the first pregnancy so that this time span varies depending on whether the animals are vaccinated before or shortly after sexual maturity. It is also important to use a reference strain to prepare the challenge. B. abortus 2308 , B. abortus 544, B. melitensis $16 \mathrm{M}$, $B$. melitensis $\mathrm{H} 38$, and $B$. ovis $\mathrm{PA}$ are the strains commonly used for this purpose. However, perusal of the literature suggests that strains 544 and H38 are more virulent than their species counterparts. The animals are usually challenged conjunctivally because it is thought that mucosae represent the normal route of entry, and the dose is adjusted so that a large number of unvaccinated controls become infected, ideally $99 \%$. This is a critical point since it is obvious that under conditions resulting in a relatively low proportion of infected controls even poor vaccines may show efficacy and, on the contrary, very strong challenges resulting in $100 \%$ infected controls are likely to mean an overdose of unknown intensity thus obscuring the performance of good vaccines. When this happens, indirect indexes such as the degree of colonization of target organs may be useful. Even though an overchallenge makes the assessment of a single vaccine difficult, it is clear that in comparative experiments differences are better revealed when stringent challenges are used.

Monitoring the results of controlled experiments is done by bacteriological procedures. This implies a thorough bacteriological search for the challenge strains Brucella in the target organs using the appropriate reference media so that quantitative or semi-quantitative data are obtained for each animal (i.e. bacteria below the threshold detection level, approximate number of bacteria per organ, number of organs colonized, etc.). Obviously, these are very expensive and laborious experiments also requiring biosafety level 3 containment facilities but they provide a solid evidence to draw conclusions, provided it is kept in mind that they relate directly to the experimental conditions.

\subsubsection{Observational field studies}

Since observational field studies should represent the "real" test, they are considered sometimes as the method of choice. However, brucellosis is a complicated disease and field evaluations may be easily biased by a number of confounding factors. These include, at least, (i), the selection of the animals to be vaccinated, which should not be done solely on the basis of serological tests; (ii), the breed, age, sex and reproductive status of the animals; (iii), the prevalence, which modulates the chances of a given animal to be exposed and the intensity of the challenge ${ }^{2}$; (iv), the

\footnotetext{
2 The higher the prevalence, the more abortions and shedders. This means not only an increased chance of a contact with contaminated materials (abortions, placenta, milk, water, food, etc.) but also higher numbers of bacteria. This is so because the numbers of viable brucella in these materials decay with time and, therefore, the probability of a contact with high numbers of viable brucella increases when there are many of such contaminations or they happen more often.
} 
method for preparing and applying the vaccine under field conditions and its standardization; (v), the general management conditions (i.e., size of the flocks, breeding systems, feeding and milking practices, handling of potentially infected animals, incidence of other diseases, etc.); (vi), basic aspects of study design such as the use and type of control groups, particularly when other health measures are simultaneously being taken (for example, removal of serologically or clinically positive animals) and when conclusions with regard to alternative vaccines are sought; (vii), the system of monitoring the disease (see below); and (viii), the time span of the observational study, which should be long enough to establish firm conclusions. Knowledge by the farmers (and researchers) of the vaccine status of the groups of the animals may also be a source of bias since it may influence the management of the animals. Ideally, a double blind system should be implemented in these studies. Obviously, it is very difficult to strictly control all these factors, or implement all controls under natural conditions. Nevertheless, adequate observational field studies are a final and necessary step if supported by the controlled studies.

Further limitations of the field studies come from the means available to monitor the effect of the vaccine. This can be performed serologically (but see point [vi] above) taking into account the specificity of the tests (i.e. their ability to differentiate vaccinated from infected animals), and also by bacteriological methods. The latter are totally specific but are limited in sensitivity both intrinsically and, in the field experiments, by the availability of samples (mostly aborted fetuses and milk). The rate of abortion as a clinical index of the disease may also be useful provided the etiological agent is identified in all or a significant number of the cases. Indeed, a reliable estimation of this index is very difficult to obtain when breeding is extensive and reports from farmers must be taken with caution. Moreover, abortion is not a constant clinical sign of infection and it has been estimated that about $20 \%$ of infected cattle never abort, and that about $80 \%$ of those that abort do so only once, some twice in successive pregnancies but rarely more than twice [29]. This means that an assessment of the rate of abortions in the whole flock may be masking the real effect of the disease because, if the disease is chronically established, abortion typically affects first pregnancy replacements. It is also important to keep in mind that if eradication is the goal, the use of this index by itself may be misleading. A decrease in the rate of abortions does not necessarily mean that animals are not infected and it is known that non aborting infected mothers act as shedders and carriers transmitting the disease both to naive animals and congenitally [102]. A reduction in the rate of abortion can be attained after massive vaccination with S19 not accompanied by removal of infected animals or other prophylactic measures and long experience shows that, although the economical impact of the disease is reduced, it results in a perpetuation of brucellosis in the flock with continuous losses and, if vaccination is stopped, outbreaks.

\section{R MUTANTS EVALUATED IN MICE}

\subsection{Against B. abortus}

\subsubsection{RB51}

The persistence in the spleen and the protection afforded by RB51 and S19 against B. abortus were first compared in mice by Stevens et al. [120], and a summary of these experiments is presented in Table II. The results show that RB51 is more attenuated in mice than S19, with shorter persistence times even at a 100 fold higher dose. In these experiments, the protection generated by RB51 was consistently and significantly lower than that of the reference $S$ vaccine 
Table II. Comparison of vaccines S19 and RB51 against B. abortus infection in BALB/c mice ${ }^{1}$.

\begin{tabular}{|c|c|c|c|c|c|}
\hline \multirow{2}{*}{ Vaccine } & \multirow{2}{*}{ Dose $^{4}$} & \multirow{2}{*}{ Persistence (weeks) ${ }^{5}$} & \multicolumn{3}{|c|}{$\begin{array}{l}\mathrm{X} \log _{10} \mathrm{CFU} \text { in spleen } \pm \mathrm{SD} \text { (units of protection) } \\
\text { at postvaccination week } \text { w }^{2,3} \text { : }\end{array}$} \\
\hline & & & 12 & 16 & 20 \\
\hline S19 & $4.2 \times 10^{6}$ & $>16$ & $2.3 \pm 0.6(4.4)^{a}$ & $1.4 \pm 0.6(4.5)^{\mathrm{a}}$ & $1.2 \pm 0.4(5.7)^{\mathrm{a}}$ \\
\hline RB51 & $5.7 \times 10^{6}$ & $=8$ & $4.6 \pm 0.4(2.1)^{\mathrm{a}, \mathrm{b}}$ & $3.3 \pm 0.6(2.6)^{a, b}$ & $5.3 \pm 0.4(1.6)^{\mathrm{a}, \mathrm{b}}$ \\
\hline RB51 & $4.6 \times 10^{8}$ & $8-12$ & $4.9 \pm 0.5(1.8)^{\mathrm{a}, \mathrm{b}}$ & $4.2 \pm 0.4(1.7)^{\mathrm{a}, \mathrm{b}}$ & $4.9 \pm 0.4(2)^{a, b}$ \\
\hline Saline & & & $6.7 \pm 0.3$ & $5.9 \pm 0.3$ & $6.9 \pm 0.1$ \\
\hline
\end{tabular}

${ }^{1}$ Adapted from Stevens et al. [120].

${ }^{2}$ Lots of mice $(n=24)$ were inoculated intraperitoneally with each vaccine. Twelve, 16 or 20 weeks after vaccination, 8 mice from each lot were challenged by the same route with $B$. abortus $2308\left(2.4 \times 10^{4}\right.$ to $4.5 \times 10^{4} \mathrm{CFU} /$ mouse), sacrificed 2 weeks after challenge, and CFU in the spleen was determined. Units of protection were calculated by subtracting the mean $\log _{10} \mathrm{CFU}$ in the spleens of vaccinated mice from the mean $\log _{10} \mathrm{CFU}$ in the spleens of saline inoculated mice.

${ }^{3}$ Statistical significance (Fisher protected least significant differences test) with respect to saline inoculated mice: ${ }^{\mathrm{a}} P<0.05$; with respect to the $\mathrm{S} 19$ inoculated mice ${ }^{\mathrm{b}} P<0.05$.

${ }^{4} \mathrm{CFU}$ administered intraperitoneally.

${ }^{5}$ Lots of 32 mice were vaccinated and slaughtered $(n=8) 2,4,8$, and 12 weeks later. The results are expressed as the time at which no animal showed a positive spleen count.

(Tab. II). These results are similar to those of other studies performed under slightly different conditions [60, 132] (see also Tabs. IV and V). RB51 has also been compared in the mouse model with other $\mathrm{R}$ strains most often with unfavorable results (see Sects. 6.1.3 and 6.1.4). Reasons for this lay probably in the accumulation in RB51 of more than a single mutation in LPS genes (see Sects. 4.2 and 6.1.3) and/or elsewhere leading to excessive attenuation.

\subsubsection{RB51WboA and RB51SOD}

Neither RB51WboA nor RB51SOD differ in their persistence in the spleens of $\mathrm{BALB} / \mathrm{c}$ mice (about 6 weeks for a $6 \times$ $10^{8} \mathrm{CFU}$ intraperitoneal dose in the experiments described in the references [132, 133]). In addition, both afford significantly better protection than RB51 in BALB/c mice, in particular RB51WboA (Tab. III). Although less than S19, RB51WboA induces significant amounts of anti-S-LPS IgG antibodies which are known to be protective (see Sect. 5.1). Thus, RB51WboA could be a better vaccine than RB51 but the interference in the serodiagnosis would have to be examined.

\subsection{3. wboA mutants other than RB51}

Mutants B. melitensis VTRM1 and B. suis VTRS1 were examined in mice by Winter et al. [135]. Inoculated intravenously at $5 \times 10^{4} \mathrm{CFU}$, both persist longer than 8 weeks in the spleens of BALB/c mice, with splenic multiplication curves similar to that of Rev 1 . They were tested against $B$. abortus, B. melitensis and B. suis (see below) in comparison with the standard S vaccines and RB51, and a summary of the experiments in which $B$. abortus 2308 was used as the challenge strain is presented in Table IV. It can be seen that the protection afforded by VTRM1 and VTRS1 is lower than that obtained with S19 but also that, despite the large differences in dose, both strains perform slightly better than RB51. Although not always statistically significant, this difference with respect to RB51 was consistently observed in experiments with other challenge strains [135]. As mentioned above, these results 
Table III. Evaluation of RB51WboA and RB51SOD in comparison with RB51 as vaccines against B. abortus infection in $\mathrm{BALB} / \mathrm{c}$ mice.

\begin{tabular}{lcccc}
\hline $\begin{array}{l}\text { Experiment } \\
\text { [reference] }\end{array}$ & Vaccine & Dose ${ }^{1}$ & $\begin{array}{c}\text { Anti-S-LPS } \\
\text { antibody }\end{array}$ & $\begin{array}{c}\text { X } \log _{10} \text { CFU in spleen } \pm \text { SD (units of } \\
\text { protection): }\end{array}$ \\
\hline $1[132]$ & RB51 & $3 \times 10^{8}$ & - & $5.0 \pm 0.2(0.7)^{\mathrm{a}}$ \\
& RB51WboA & $3 \times 10^{8}$ & ++ & $0.5 \pm 0.0(5.1)^{\mathrm{b}}$ \\
$2[133]$ & Saline & & & $5.7 \pm 0.1$ \\
& RB51 & $4 \times 10^{8}$ & - & $4.6 \pm 0.5(0.8)$ \\
& RB51SOD & $4 \times 10^{8}$ & - & $2.9 \pm 1.8(2.5)^{\mathrm{c}}$ \\
& Saline & & - & $5.4 \pm 0.3$ \\
\hline
\end{tabular}

${ }^{1} \mathrm{CFU}$ administered intraperitoneally.

2 The results are expressed as follows: -, no antibody; +++, amount of antibody generating $50 \%$ of the OD generated by sera from S19 infected mice in an ELISA-IgG.

${ }^{3}$ Lots of BALB/ c mice ( $n=5$ in Experiment 1 and $n=7$ in Experiment 2) were inoculated intraperitoneally with the vaccine strain or saline, challenged by the same route with B. abortus 23087 weeks after vaccination, and spleen $\mathrm{CFU}$ were determined 2 weeks later. Units of protection were calculated by subtracting the mean $\log _{10} \mathrm{CFU}$ in the spleens of vaccinated mice from the mean $\log _{10} \mathrm{CFU}$ in the spleens of saline inoculated mice.

${ }^{4}$ Statistical significance (Student $t$ test) with respect to saline (Experiment 1 ): ${ }^{\mathrm{a}} P<0.001$; ${ }^{\text {b }} P<0.0001$; or with respect to RB51 (Experiment 2): ${ }^{\mathrm{c}} P<0.01$.

Table IV. Evaluation of mutants VTRM1 and VTRS1 in comparison with RB51 and S19 as vaccines against $B$. abortus infection in BALB/c mice ${ }^{1}$.

\begin{tabular}{lcc}
\hline Vaccine & Dose (route) & X $\log _{10}$ CFU in spleen \pm SD (units of protection) ${ }^{3,4}$ \\
\hline S19 & $5 \times 10^{3}(\mathrm{IV})$ & $3.42 \pm 0.57(3.24)^{\mathrm{a}}$ \\
RB51 & $5 \times 10^{8}(\mathrm{IP})$ & $5.78 \pm 0.58(0.88)^{\mathrm{b}}$ \\
VTRM1 & $5 \times 10^{4}(\mathrm{IV})$ & $5.40 \pm 0.68(1.26)^{\mathrm{b}}$ \\
VTRS1 & $5 \times 10^{4}(\mathrm{IV})$ & $5.25 \pm 0.95(1.41)^{\mathrm{c}}$ \\
None & & $6.66 \pm 0.35$ \\
\hline
\end{tabular}

${ }^{1}$ Data are from Winter et al. [135].

${ }^{2} \mathrm{CFU}$ administered intravenously (IV) or intraperitoneally (IP).

${ }^{3}$ Lots of BALB/c mice $(n=5)$ were inoculated with the vaccine or left unvaccinated, challenged IP with B. abortus $2308\left(5 \times 10^{4} \mathrm{CFU} /\right.$ mouse) 8 weeks after vaccination and spleen CFU were determined two weeks later. Units of protection were calculated by subtracting the mean $\log _{10} \mathrm{CFU}$ in the spleens of vaccinated mice from the mean $\log _{10} \mathrm{CFU}$ in the spleens of non vaccinated mice.

${ }^{4}$ Statistical significance (Student $t$ test) with respect to non vaccinated mice: ${ }^{\text {a }} P<0.001 ;{ }^{\text {b }} P<0.01$;

c $P<0.05$.

suggest that RB51 carries mutations in genes other than wboA.

\subsubsection{Mutants in the wbk region}

The experiments carried out with these mutants (and also with LPS core mutants) are summarized in Table V. It is noteworthy that both 2.17 wbkA and 9.49 per show the same $\mathrm{RT}_{50}$ as the reference vaccine S19 (however, the doses were different). This result is consistent with the observation by Godfroid et al. [50] that B. melitensis per mutants keep the ability to multiply in cultured bovine macrophages. With regard to protection, there are three obvious comments on the data of Table V. First, S19 is the best vaccine in terms of 
Table V. Evaluation of O-polysaccharide $(9.49,2.17)$ and core $(80.16$, and 55.30) LPS mutants in comparison with RB51 and S19 as vaccines against B. abortus and B. ovis infection in BALB/c mice ${ }^{1}$.

\begin{tabular}{|c|c|c|c|c|}
\hline \multirow{2}{*}{ Vaccine } & \multirow{2}{*}{ Dose (route) ${ }^{4}$} & \multirow{2}{*}{$\begin{array}{c}\text { Persistence } \\
\left(\mathrm{RT}_{50} \text { in weeks) }\right.\end{array}$} & \multicolumn{2}{|c|}{$\begin{array}{l}\mathrm{X} \log _{10} \mathrm{CFU} \text { in spleen } \pm \mathrm{SD} \\
\text { (units of protection) of challenge strain } 2,3\end{array}$} \\
\hline & & & B. abortus 2308 & B. ovis $\mathrm{PA}$ \\
\hline S19 & $1 \times 10^{5}(\mathrm{SC})$ & 7.8 & $1.92 \pm 0.65(3.95)^{a}, \mathrm{e}$ & $2.09 \pm 1.83(2.31)^{b, i}$ \\
\hline RB51 & $1 \times 10^{8}(\mathrm{IP})$ & 3.8 & $4.87 \pm 0.19(0.64)^{b, c}$ & $2.10 \pm 2.29(3.11)^{b, f}$ \\
\hline $9.49 \mathrm{per}$ & $1 \times 10^{8}(\mathrm{IP})$ & 7.8 & $3.44 \pm 1.37(2.07) a, c, e$ & $2.35 \pm 2.51(2.86)^{b, f, i}$ \\
\hline $2.17 w b k A$ & $1 \times 10^{8}(\mathrm{IP})$ & 7.8 & $3.27 \pm 2.02(2.24) a, c, e$ & $0.61 \pm 0.07(4.60)^{a, f, i}$ \\
\hline $80.16 w a^{* *}$ & $1 \times 10^{8}(\mathrm{IP})$ & 3.8 & $5.24 \pm 0.17(0.27)^{b, c, f}$ & $4.07 \pm 2.15(1.14)^{c, e, ~ i ~}$ \\
\hline $55.30 \mathrm{manB}_{\text {core }}$ & $1 \times 10^{8}(\mathrm{IP})$ & 7.8 & $5.43 \pm 0.26(0.08)^{b, c, f}$ & $5.66 \pm 0.32(0.00)^{c}, e, g$ \\
\hline $\begin{array}{l}\text { Phosphate buffered } \\
\text { saline }\end{array}$ & & & $5.51 \pm 0.12$ & $5.21 \pm 0.52$ \\
\hline
\end{tabular}

${ }^{1}$ Data are from Monreal et al. [78].

${ }^{2}$ Groups of 5 mice were vaccinated with the doses indicated, challenged IP 4 weeks later with either B. abortus 2308 or B. ovis PA (both at $10^{5} \mathrm{CFU} /$ mouse) and spleen CFU of the challenge strain were determined two weeks later. Units of protection were calculated by subtracting the mean $\log _{10} \mathrm{CFU}$ in the spleens of vaccinated mice from the mean $\log _{10} \mathrm{CFU}$ in the spleens of mice inoculated with phosphate buffered saline.

${ }^{3}$ Statistical significance (Fisher Protected Least Significant Differences test): in comparison with phosphate buffered saline vaccinated group: ${ }^{\mathrm{a}} P=0.05 ;{ }^{\mathrm{b}}$ not significant; in comparison with $\mathrm{S} 19$ reference vaccinated group: ${ }^{\mathrm{c}} P=0.05 ;{ }^{\mathrm{d}}$ not significant; in comparison with the RB51 vaccinated group: ${ }^{\mathrm{e}} P=0.05$; ${ }^{\mathrm{f}}$ not significant.

${ }^{4} \mathrm{CFU}$ administered subcutaneously (SC) or intraperitoneally (IP).

residual virulence $\left(\mathrm{RT}_{50}\right)$ and immunogenicity. Second, $2.17 w b k A$ and 9.49 per perform satisfactorily when these two parameters are considered, and these $w b k$ mutants are the only protective $R$ vaccines under the experimental conditions. Third, neither RB51 nor the mutants with core defects protect significantly.

\subsubsection{Mutants in genes affecting the LPS core structure}

Two of these mutants have been analyzed in comparison with the $w b k$ mutants (Tab. V). B. abortus 55.30, the $\operatorname{man} B_{\text {core }}$ mutant carrying the most severe core defect (Tab. I), shows an $\mathrm{RT}_{50}$ similar to that of 9.49 per and $2.17 w b k A$. This is not in contradiction with the report by Allen et al. [3] that a $B$. abortus $m a n B_{\text {core }}(r f b k)$ mutant is practically avirulent in $\mathrm{Balb} / \mathrm{c}$ mice because these authors used a much lower dose in their experiments. The inner core-deficient $80.16 w^{* *}$ mutant shows a shorter $\mathrm{RT}_{50}$ (similar to that of RB51), and a comparison with the $\operatorname{man} B_{\text {core }}$ mutant suggests that not all core sections are equally important in virulence. Explanations for this could relate to different interactions with bactericidal polycations, increased in $80.16 w a^{* *}$ with respect to $55.30 \mathrm{manB}_{\text {core }}$ [78]. The failure of these two core mutants to induce significant protection has been pointed out above. The contrast between the good $\mathrm{RT}_{50}$ of mutant $55.30 \mathrm{manB}_{\text {core }}$ and the poor protection it affords as a vaccine is noteworthy. It seems that, although not equally important in virulence, all core epitopes are important in inducing immunity.

There are no studies on the efficacy of the mutant B. abortus $\mathrm{B} 2211$ pgm as a vaccine and only data on their persistence. 
$\mathrm{BALB} / \mathrm{c}$ mice injected intraperitoneally with $10^{5} \mathrm{CFU}$ of this mutant clear the splenic infection in less than 2 weeks [126]. To compare this result with those obtained with other core mutants in the above-summarized studies is not possible owing to the wide dose differences. However, this persistence is much shorter than that of the wboA mutants (see Sect. 6.1.3) which inoculated at a similar dose $\left(5 \times 10^{5} \mathrm{CFU}\right)$ persisted for about 7 weeks [135]. As mentioned above, dysfunction of pgm affects (at least) the LPS and the periplasmic $\beta(1,2)$ cyclic glucans which act as virulence factors [19]. On this basis, it can be speculated that this mutant is overattenuated in mice.

\subsection{Against $B$. melitensis and $B$. suis}

The VTRM1 and VTRS1 mutants have also been evaluated for their ability to protect mice against $B$. melitensis and $B$. suis (biovars 1 and 4) in comparison with RB51, S19 and Rev 1 [135]. The experiments reproduced the results summarized above (see Sect. 6.1.3): the protection achieved with the $\mathrm{S}$ vaccines and VTRM1 and VTRS1 was slightly better than that obtained with RB51 and the best result was obtained with the standard S vaccine. Protection against $B$. melitensis had been observed before in RB51 vaccinated mice by Jiménez de Bagüés et al. [60] but their study did not include reference vaccine strains for comparative purposes.

\subsection{Against B. ovis}

B. ovis is a naturally $\mathrm{R}$ species and, although it lacks the O-PS characteristic of the $\mathrm{S}$ Brucella species, it is virulent in sheep. B. melitensis Rev 1 is the vaccine currently used for $B$. ovis immunoprophylaxis but, since there is no role for anti O-PS antibodies in protection in this case, it can be predicted that $R$ vaccines should be more effective against $B$. ovis than against S Brucella. RB51 was first tested against $B$. ovis in the mouse model in the experiments of Jiménez de Bagüés et al.
[60]. These authors observed that RB51 induced a protection against $B$. ovis comparable to that obtained against $B$. abortus and B. melitensis $(2.30,2.03$ and 1.72 protection units, respectively) but, as mentioned above, this study did not include $\mathrm{S}$ vaccine strains for comparative purposes. On the contrary, mutant VTRM1 has been compared with Rev 1 [135], and the protection afforded against the $B$. ovis PA strain was similar for both vaccines (1.92 and 1.58 protection units, respectively).

The protective efficacy against $B$. ovis of mutants 9.49 per, 2.17 wbkA, 80.16 $w a^{* *}$, and 55.30 manB $_{\text {core }}$ has also been studied in comparison with RB51 and S19 (Tab. V). Mutants 9.49 per and 2.17 wbkA as well as S19 and RB51 afforded significant protection with no statistically significant differences among them. However, it was observed in these experiments that all mice vaccinated with 2.17 wbkA cleared the infection whereas 3 out of the 5 mice vaccinated with 9.49 per, RB51 or S19 remained infected at slaughter [78]. In parallel with the results obtained against B. abortus, mutants with core defects did not protect against virulent $B$. ovis, which further supports the conclusion that an intact core is required for maximal vaccine efficacy in mice.

\section{R VACCINES TESTED IN CATTLE}

\subsection{B. abortus $45 / 20$}

Vaccine 45/20 was used as a bacterin about 25 years ago for controlling $B$. abortus infection in cattle [84] and it was reportedly useful in some European Union countries $[84,106]$. The standard conditions in these countries were, however, proficient sanitary services, intensive breeding, good animal management practices and low prevalence. Under these conditions, it is extremely difficult to distinguish the effect of the vaccine from the one that would be caused by the sanitary measures 
by themselves, and experiences in other situations were much less favorable [84]. The results of controlled experiments are satisfactory in some cases but not in others [8, 84, 124], and direct comparisons with S19 unfavorable $[8,124]$. Moreover, the quality of the vaccine was a constant source of problems [28]. The use of this vaccine was abandoned when the problems in the serological tests associated to $\mathrm{S} 19$ vaccination were considerably reduced by the development of more specific serological tests, the use of the conjunctival route of vaccination and the demonstration of the usefulness of the reduced S19 doses in adult cattle [84].

\subsection{B. abortus RB51}

\subsubsection{Interference in S-LPS tests}

As expected, $100 \%$ of the cattle subcutaneously vaccinated with RB51 develop antibodies to $\mathrm{R}$ antigens that can be detected in a dot ELISA and other tests [89, 91, 93, $95,119]$. On the contrary, vaccination with RB51 does not significantly interfere in classical tests such as the rose bengal, tube agglutination and the complement fixation test [21, 22, 45, 95, 117-119, 137]. Low numbers of positive reactions in rapid agglutination tests have been noticed after RB51 revaccination of adults previously vaccinated with S19 during calfhood but the same sera were negative in confirmatory test [89]. Some authors have reported that this revaccination induces antibodies detectable in tube serum agglutination and competitive ELISA in animals that had had persistent reactions in rapid agglutination tests [127] but others have not made this same observation [111]. Classical tests use suspensions of S brucellae where the LPS core (shared totally or partially by $\mathrm{S}$ and $\mathrm{R}$ brucellae) is not exposed and, therefore, the anti R-LPS antibodies elicited by RB51 are not detected. In immunosorbent tests with S-LPS, or in tests using the LPS polysaccharide obtained by acid hydrolysis, the core epitopes (shared by the S and R LPS) become accessible to antibodies. Moreover, it is well known that LPS extracts from $\mathrm{S}$ brucellae always contain significant amounts (up to $10 \%$ ) of R-LPS normally present in the surface of these bacteria. It is therefore possible that $R$ vaccines show some degree of interference in these tests. It has been repeatedly reported that the full dose of RB51 in calves and the use of RB51 as a booster vaccine in adults that had been vaccinated with S19 during calfhood do not elicit antibodies detectable in the indirect ELISA [45, 111, 117]. However, we have observed that the indirect ELISA with S-LPS is positive in a significant proportion of RB51 vaccinated sheep and also in RB51 vaccinated cattle negative in the rose bengal test (Marín C.M., Blasco J.M., Moreno E., unpublished results), which suggests that attention should be paid to the standardization of the S-LPS ELISA when vaccination with RB51 is implemented. Two doses of RB51 administered on a 30 day interval have been reported to induce antibodies to S B. abortus 99 detectable in a Coombs antiimmunoglobulin test [23]. The specificity of these antibodies has not been determined with purified antigens and this protocol of vaccination is unusual. The actual importance of these problems is not known and they are possibly shared by all $\mathrm{R}$ vaccines.

\subsubsection{Safety}

As mentioned in the Introduction, S19 can induce abortion in a small proportion of adult vaccinated cows (about 1\% depending on the pregnancy status) and genital problems in bulls. Thus, it is of interest to know to what extent this problem could be solved by any $\mathrm{R}$ vaccine. The experiments in mice suggest that the abortifacient effect of RB51 is reduced as compared to that of S19 [112] but studies on bovine chorioallantoic explants do not show differences between the cytotoxicity of these two strains [110].

In the natural hosts, the safety of a live brucellosis vaccine (i.e. no shedding of the viable vaccine and no abortifacient effects) 
depends on several factors. The most important ones are the route and dose of vaccination and the status and period of pregnancy of the animals. The abortifacient effect of live brucellosis vaccines becomes apparent when the animals are vaccinated during mid pregnancy (5-6 or 2-3 months for cattle and sheep, respectively) since there is a time interval (1.5-2 months in both species) for the lesions leading to abortion to develop. Shedding may happen via vaginal excretion, aborted fetuses or milk.

RB51 is licensed (in the US) only for use in young replacement animals at 1-3.4x $10^{10} \mathrm{CFU}$ (full dose) by the subcutaneous route [39]. Some authors have determined the innocuousness of this dose administered intramuscularly [39], but the protective efficacy of this method of vaccination is unknown. Administered intravenously at full doses in pregnant cattle, RB51 can infect the bovine placenta, mammary gland, and fetus, inducing placentitis and, in some cases, delivery of premature and weak calves [93]. This route represents a severe test and is not used for vaccination, but the results show that RB51 is not exempt of risks. In fact, there is a reported case of necrotizing placentitis and endometritis with fetus colonization and abortion caused in a pregnant heifer vaccinated with the full dose of RB51 by the recommended subcutaneous route [128]. The actual importance of this under field conditions cannot be presently evaluated since there is a paucity of contrasted data in peer-reviewed publications. Some authors claim that RB51 practically does not cause abortions in pregnant heifers when used at the full dose [86] and, according to unpublished results obtained by the manufacturer (cited in reference [88]), the vaccination of 624 pregnant cattle resulted in only one abortion and milk excretion caused by the vaccine. Others, however, have associated the use of RB51 in 3-5 month pregnant cows in mass vaccination trials in Chile with vaccineinduced abortions and isolated this vaccine from high numbers of aborted cattle and also from cows at the moment of parturition [66]. The abortions took place 2.53.4 months after vaccination with RB51 [66], an interval similar to that described in abortions induced in sheep by $B$. melitensis Rev 1 [17].

The use of a reduced dose $\left(10^{9}\right.$ UFC) of S19 in adult cattle lowers the rate of abortion and milk excretion [84]. This idea has been extrapolated to RB51, and it has been shown that inoculation at $5 \times 10^{7} \mathrm{CFU}$ is safe [137]. However this highly reduced dose $\left(10^{9} \mathrm{CFU}\right.$ is the proposed reduced dose for adult vaccination with RB51) seems too low to induce effective immunity (see Sect. 7.2.3). In a comparative study with a short number of animals $(n=$ 5 in each group), neither RB51 nor S19 administered subcutaneously (9.4 and $3 \times$ $10^{8} \mathrm{CFU}$, respectively) caused abortions or placentitis lesions [95]. In two experiments with 57 and 13 strain 19 calfhoodvaccinated cattle, revaccination with the reduced dose of RB51 did not also cause abortion [111, 127]. However, the booster vaccine (see Sect. 7.2.6) was applied in late (7-8 months) pregnancy and this precludes firm conclusions on the abortifacient effect. In one of these experiments, RB51 was excreted in milk by near the half $(6 / 13)$ of vaccinated cows, and in one case for up to 69 days after vaccination [127]. Obviously, the release of a bacterium carrying rifampicin resistance into the environment is of concern (see also Sect. 4.2).

\subsubsection{Protection against $B$. abortus in controlled experiments}

Table VI summarizes the results of the five controlled experiments in which RB51 has been evaluated in cattle, either alone or in comparison with the reference vaccine S19, and which are susceptible to statistical analysis. Experiments 1 (full dose, orally) and 2 (reduced dose, subcutaneously) were performed in adult cattle. Experiments 3, 4 and 5 were performed in groups of calves vaccinated subcutaneously with the reduced 
Table VI. Summary of controlled experiments designed to evaluate RB51 in cattle.

\begin{tabular}{lcccccccc}
\hline $\begin{array}{l}\text { Experiment } \\
\text { [reference] }\end{array}$ & Vaccine & Dose & Route & $\begin{array}{c}\text { No. of } \\
\text { animals }\end{array}$ & $\begin{array}{c}\text { Age at } \\
\text { vaccination } \\
\text { (months) }\end{array}$ & $\begin{array}{c}\text { Vaccination- } \\
\text { challenge interval } \\
\text { (months) }\end{array}$ & $\begin{array}{c}\text { No. } \\
\text { infected } \\
(\%)^{3}\end{array}$ & $\begin{array}{c}\text { No. } \\
\text { aborted } \\
(\%)\end{array}$ \\
\hline $1[41]$ & RB51 & $\geq 1 \times 10^{10}$ & OR & 10 & 18 & 7.5 & $2(20)$ & $3(30)$ \\
& Saline & & OR & 10 & 18 & 7.5 & $8(80)$ & $7(70)$ \\
$2[88]$ & RB51 & $1-3 \times 10^{9}$ & SC & 11 & 18 & 6 & $0(0)$ & $0(0)$ \\
& Saline & & SC & 6 & 18 & 6 & $6(100)$ & $4(67)$ \\
$3[87]$ & RB51 & $1 \times 10^{9}$ & SC & 4 & $3-6$ & $14-21$ & $4(100)^{4}$ & $2(50)^{4}$ \\
& RB51 & $1 \times 10^{10}$ & SC & 26 & $3-6$ & $14-21$ & $12(46)^{4}$ & $3(11)^{4}$ \\
& Saline & & SC & 15 & $3-6$ & $14-21$ & $10(67)^{4}$ & $7(47)^{4}$ \\
$4[22]$ & RB51 & $1 \times 10^{10}$ & SC & 29 & $3-10$ & $12-21$ & $3(11)^{4}$ & n.d. ${ }^{5}$ \\
& S19 & $1 \times 10^{10}$ & SC & 22 & $3-10$ & $12-21$ & $1(5)^{4}$ & n.d. ${ }^{5}$ \\
& Saline & & SC & 20 & $3-10$ & $12-21$ & $12(60)^{4}$ & n.d. ${ }^{5}$ \\
$5[14,15]$ & RB51 & $1 \times 10^{10}$ & SC & 24 & 9 & $9-14$ & $20(83.3)^{4}$ & n.d. ${ }^{5}$ \\
& S19 & $1 \times 10^{10}$ & SC & 29 & 9 & $9-14$ & $18(62)^{4}$ & n.d. ${ }^{5}$ \\
& None & & SC & 22 & 9 & $9-14$ & $22(100)^{4}$ & n.d. ${ }^{5}$ \\
\hline
\end{tabular}

${ }^{1} \mathrm{SC}$, subcutaneous; OR, oral.

${ }^{2}$ For Experiment 2, the groups vaccinated with $1 \times 10^{9}$ and $3 \times 10^{9}$ are pooled (see also text); for Experiment 3 , only the animals that could be necropsied and observed for abortion are included.

${ }^{3}$ In all experiments, infection was defined by bacteriological isolation of the challenge strain (B. abortus 2308 in all cases). In Experiment 1, the samples cultured were vaginal fluids and milk obtained at days 3 and 14 after parturition, and parotid, iliac and mammary lymph nodes obtained at necropsy but only in the non-excretors 2 months after parturition; lungs and abomasal fluids of fetuses were also examined. In Experiments 2, 3, 4 and 5, a thorough bacteriological search was performed which included (at least) samples of blood, milk, vaginal fluids, placenta and, after necropsy, mammary gland, spleen, liver, and the most important lymph nodes.

${ }^{4}$ The figures are the pooled results of the different age groups in each experiment.

5 n.d., no data (no or only part of the animals in the study were pregnant).

(Experiment 3) or the full dose (Experiments 3, 4 and 5). In two experiments (3 and 5), a comparison with $\mathrm{S} 19$ was made. In all cases, the challenge strain was $B$. abortus 2308 and infection was defined by bacteriological culture. In Experiment 1, however, the bacteriological study was not as thorough and timely as in the other experiments (see footnotes of Tab. VI), a factor which may bias the results.

The data presented in the original publications are analyzed in Table VII. The parameters calculated are the etiologic fraction (EF) and the relative risk (RR) of infection (and its 95\% confidence interval) [73]. In the context of the experiments, the \%EF is the proportion of animals whose infection is actually attributable either to the absence of vaccination (when the non vaccinated and vaccinated groups are compared) or to the relative failure of a vaccine (when two groups vaccinated with two different vaccines are compared). $\mathrm{RR}$ is the ratio between the rate of infection in the non vaccinated versus vaccinated (either RB51 or S19) or the RB51 versus S19 vaccinated groups. According to these parameters, non vaccinated animals have a 1.1 to 14.3 times higher risk of becoming infected than RB51 orally vaccinated adult animals (Experiment 1 ). It is worth noting that only $20 \%$ of the RB51 vaccinated animals developed 
Table VII. Etiologic fraction (EF) and relative risk (RR) calculated with the results of experiments in which RB51 has been evaluated in cattle.

\begin{tabular}{|c|c|c|c|c|}
\hline Experiment [reference] & Comparisons & RR (95\% confidence interval) & $\mathrm{EF}(\%)$ & $P$ \\
\hline \multirow[t]{2}{*}{$1[41]$} & Saline versus RB51 (infection) & $4.0(1.1-14.3)$ & 75 & $<0.01$ \\
\hline & Saline versus RB51(abortion) & $2.3(0.8-6.5)$ & 56 & 0.07 \\
\hline \multirow[t]{2}{*}{$2[88]$} & Saline versus RB51 (infection) & u. ${ }^{1}$ & 100 & $<0.01$ \\
\hline & Saline versus RB51 (abortion) & u. ${ }^{1}$ & 100 & $<0.01$ \\
\hline \multirow[t]{2}{*}{$3[87]$} & Saline versus RB51 (infection) ${ }^{2}$ & $1.4(0.8-2.5)$ & 31 & 0.20 \\
\hline & Saline versus RB51 (abortion) ${ }^{2}$ & $2.2(0.8-5.8)$ & 54 & 0.31 \\
\hline \multirow[t]{3}{*}{4 [22] } & Saline versus RB51 & $5.8(1.9-17.9)$ & 83 & $<0.01$ \\
\hline & Saline versus S19 & $13.2(1.9-92.6)$ & 92 & $<0.01$ \\
\hline & RB51 versus S19 & $2.3(0.3-20.4)$ & 56 & 0.60 \\
\hline \multirow[t]{3}{*}{$5[14,15]$} & No vaccine versus RB51 & $1.2(1.0-1.4)$ & 17 & 0.11 \\
\hline & No vaccine versus S19 & $1.6(1.2-2.1)$ & 38 & $<0.01$ \\
\hline & RB51 versus S19 & $1.3(0.9-1.9)$ & 25 & 0.16 \\
\hline
\end{tabular}

antibodies to the vaccine, a result in clear contrast with that obtained by the subcutaneous route (see Sect. 7.2.1). Although correct dosage and environmental safety may be serious problems, the oral route has been considered mostly as a possibility to vaccinate wildlife [41, 65] or small ruminants under extensive management conditions in semidesertic areas [83, 136]. The results obtained with RB51 illustrate that routes alternative to the subcutaneous one deserve attention but because of the differences in bacteriological procedures noted above, to reach a clear conclusion on its usefulness to administer $R$ vaccines is not presently possible. Experiment 2 was also performed in adult cattle but using a reduced subcutaneous dose and, although it is not possible to calculate exact figures for RR, the EF for this study was $100 \%$ and it is obvious that the differences with the non vaccinated group are very large. Surprisingly, the reduced dose was totally ineffective in calves (Experiment 3, Tab. VI). This contrast between Experiments 2 and 3 (reduced dose) is striking, and there may be at least two possible explanations. First, it is possible that the age at vaccination is decisive to evoke a protective immune response by RB51. On the basis of previous evidence, it has been suggested [84] that the protection given by $\mathrm{S} 19$ and $45 / 20$ to adult cattle is greater than that of cattle vaccinated as calves and this could perhaps apply to the results obtained with RB51. However, when the evidence $[8,124]$ is examined it becomes apparent that the comparisons may be biased in favor of a more protective effect in adults by the shorter time elapsed between vaccination and challenge. Thus, a second explanation for the discrepancies observed between Experiments 2 and 3 (reduced dose) may lay in the different vaccination-challenge periods, which was at least two times longer in the animals vaccinated at calfhood that were not protected (Tab. VI).

The results obtained with the full dose of RB51 in calves in the different experiments is also apparently contradictory. Whereas Experiments 3 (full dose) and 5 show no significant differences between the RB51 
vaccinated and the non vaccinated groups, in Experiment 4 the differences were significant. As shown in Tables VI and VII, the two experiments in which RB51 failed to confer statistically significant protection to calves had a higher percentage of infected controls. Accordingly, as illustrated by the grading $\mathrm{RR}$ and $\mathrm{EF}$ values derived from these experiments (Tab. VII), the simplest explanation for the apparent discrepancy among Experiments 3,4 and 5 is that the immunity afforded by RB51 to calves is progressively overcome as the challenge efficacy (i.e. the number of controls infected) increases. In contrast, the differences between S19 vaccinated and non vaccinated calves remain highly significant under both the less (Experiment 3) and the most (Experiment 4) stringent challenges, and the differences between S19 and RB51 become more apparent in the most stringent experiment. Experiment 4 is cited in the literature as the demonstration that S19 and RB51 are similarly effective in protecting cattle $[68,111$, 113] but without a description of the particular experimental conditions (i.e. the low $\%$ of infected controls) this presently seems an overstatement. An additional point is the apparent reduction (not statistically significant) in abortions caused by RB51 (Tabs. VI and VII). Although this effect has been suggested as a positive trait of RB51 even if infection is not prevented [86, 87], it has to be kept in mind that, by itself, protection against abortion but not against infection (and shedding) is not useful to attain eradication (see Sect. 5.3).

\subsubsection{Protection against $B$. abortus according to field experiments and observational studies}

RB51 has been reported by Lord et al. [68] to be much more effective than S19 under field conditions. In their study, serologically negative calves (the Zebu type of 3 to 8 months of age) belonging to two infected herds (one with 39\% and the other with $2 \%$ seroprevalence) were vaccinated subcutaneously with the reduced dose $(5 \times$ $10^{9} \mathrm{CFU}$ ) of RB51 or S19 and kept in the same herd for 240 days. The follow-up consisted of serological testing using a panel of 6 tests, including an agar immunodiffusion test with a Brucella polysaccharide (native hapten or polysaccharide $B$ ) and a rapid plate agglutination test. Used in gel diffusion tests, this Brucella polysaccharide precipitates with the sera of infected but not $\mathrm{S} 19$ vaccinated cattle [33-35, 63, 67] even from heavily infected herds [63] and positive results can thus be taken as an index of infection. On the contrary, the plate agglutination test is very sensitive but not specific in differentiating infected from S19 vaccinated cattle and is an index of exposure (followed or not by infection) to an S strain (either S19 or a field strain). Also, some animals were bred to seropositive bulls and the abortions were recorded.

A summary of the results of this field experiment is presented in Table VIII. They showed that RB51 was a much better vaccine than $\mathrm{S} 19$, with a protection rate of $100 \%$ even in the herd with $39 \%$ seroprevalence or in the animals bred to seropositive bulls. These results are in marked contradiction with those of the controlled experiments in which comparisons with S19 were made; none hinted at the superiority of RB51 and, on the contrary, some suggest or prove that S19 is a better vaccine when all parameters are made equal for the groups tested and that the reduced dose is not protective in calves. This field experiment has a flaw in the selection of the animals to be vaccinated. They belonged to infected flocks and were chosen on the basis of a negative serology, but this method overlooks the fact that some animals acquire latent infections not manifested as a positive serology (reviewed in reference [123]). It is, however, difficult to see how this could have introduced a bias in the selection of only one of the groups to be vaccinated. It is also remarkable that none of the RB51 vaccinated animals, including those bred to seropositive bulls, 
Table VIII. Summary of a comparative field evaluation of RB51 and S191.

\begin{tabular}{|c|c|c|c|c|c|}
\hline \multirow{2}{*}{$\begin{array}{l}\text { Herd } \\
\text { (\% seroprevalence) }\end{array}$} & \multirow{2}{*}{ Vaccine } & \multirow{2}{*}{$\begin{array}{c}\text { No. } \\
\text { of animals }\end{array}$} & \multicolumn{2}{|c|}{ No. of animals $(\%)$ positive in: } & \multirow{2}{*}{$\begin{array}{l}\text { No. of dams aborted / } \\
\text { No. bred to seropositive } \\
\text { bulls (\%) }\end{array}$} \\
\hline & & & RPAT $^{2}$ & AGID $^{3}$ & \\
\hline \multirow[t]{3}{*}{ A (39) } & S19 & 75 & $23(30.7)$ & $8(10.7)$ & $11 / 20(55.0)$ \\
\hline & RB51 & 140 & $0(0.0)$ & $0(0.0)$ & $0 / 44(0.0)$ \\
\hline & None & 40 & $18(45.0)$ & $18(45.0)$ & $18 / 20(90.0)$ \\
\hline \multirow[t]{3}{*}{ B (2) } & S19 & 90 & $8(8.9)$ & $0(0.0)$ & $3 / 10(30.0)$ \\
\hline & RB51 & 150 & $0(0.0)$ & $0(0.0)$ & $0 / 30(0.0)$ \\
\hline & None & 40 & $18(45.0)$ & $8(20.0)$ & $8 / 20(40.0)$ \\
\hline
\end{tabular}

${ }^{1}$ Data are from Lord et al. [68].

${ }^{2}$ Rapid plate agglutination test.

${ }^{3}$ Agar gel immunodiffusion test with Brucella polysaccharide.

became positive in the plate agglutination test (Tab. VIII). This would be an expected event since the controlled experiments show that, when challenged, even the animals vaccinated with RB51 which do not become infected develop a positive serology in agglutination tests [22, 41, 87].

Figure 3 shows the results of observations carried out by one of us on five independent dairy farms of the highlands of Costa Rica. The farms were similar in that replacement animals were kept in the same herd in which they were born, reproduction was always conducted through artificial insemination and no purchase of external replacements was made. Vaccine S19 was applied subcutaneously at the full standard dose until 1996 when the S19 reduced dose $\left(10^{9} \mathrm{CFU}\right)$ method was introduced. In 1999, S19 was replaced by RB51 (full dose). No matter the vaccine, only young replacement animals were vaccinated in all herds. The sera of all aborted heifers had a strongly positive result in the rose bengal or serum agglutination and 2-mercaptoethanol tests. Sera taken in year 2000 from aborted cows were also tested in the competitive ELISA (a test which is highly specific in detecting infected animals [85]) with positive results. Moreover, B. abortus biovar 2 was isolated from aborted fetuses surveyed in all five herds during the obser- vational period. Due to economical constraints and to the fact that the rates of abortion during the second and successive pregnancies became low and tolerable by farmers (the overall abortion rate in each farm seldom reached $10 \%$ until year 2000), seropositive animals were not removed during the years in which S19 vaccination was used. Figure 3 shows that the introduction of the reduced dose of S19 was followed by a peak in the abortion rates of first parturition heifers in most farms. It can also be seen that the introduction of RB51 did not improve the situation and that, in fact, the percentage of abortions in all farms was higher than in any of the preceding years. Although the results of observations based on historical controls are prone to be affected by confounding factors, the simultaneous increase of abortions in five independent farms in coincidence with the replacement of S19 by RB51 is remarkable.

\subsubsection{Protection against B. melitensis}

B. melitensis infection of cattle is becoming a frequent finding in countries with moderate or high prevalence of this infection in small ruminants. Thus, an effective vaccine in cattle should confer protection against both $B$. abortus and 


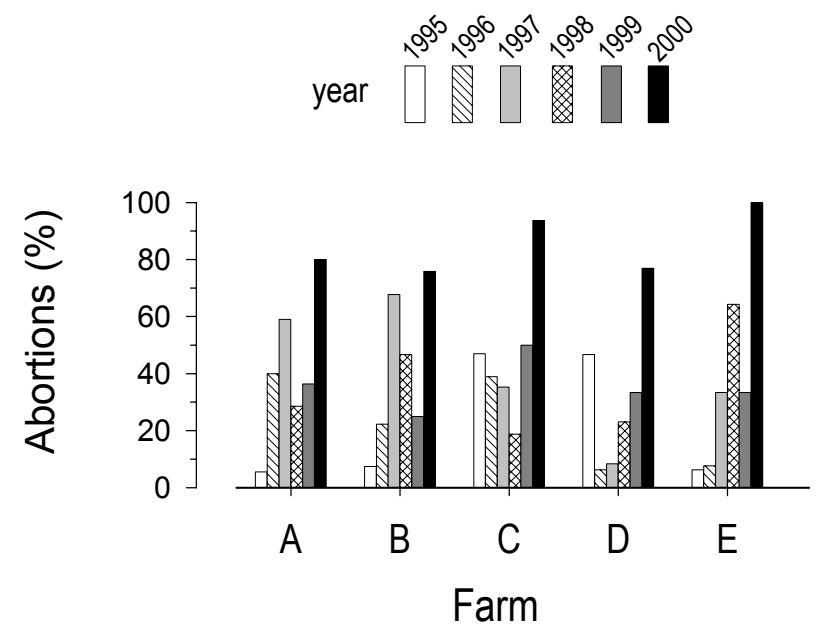

Figure 3. Evolution of abortion in first parturition heifers belonging to five independent $B$. abortus (biovar 2) infected dairy farms (A to E) of the high lands of Costa Rica. The replacement heifers were kept in the same farm in which they were born, reproduction was always conducted through artificial insemination, and no purchase of external replacements was made in any herd. No positive animal was culled through the years reported. Replacement heifers were vaccinated subcutaneously with the standard dose of S19 until 1996 when the reduced dose was introduced. In 1999, S19 was replaced by RB51 (full dose). The sera of all aborted heifers had a strongly positive serological results (confirmed by competitive ELISA in year 2000) and B. abortus biotype 2 was isolated in all five farms.

B. melitensis. There are only limited studies on the protection afforded by S19 against B. melitensis in cattle, but they indicate that S19 induces useful immunity [59]. No information exists on the efficacy of RB51 against this heterologous infection.

\subsubsection{RB51 as a booster vaccine}

As discussed above (Sect. 7.2.3), it is likely that the protection afforded by vaccination during calfhood wanes significantly in a relatively short time. However, repeated use of any classical $S$ vaccine would aggravate the problem of interpreting the serological tests (see Sect. 1). On these premises, revaccination with an effective $R$ vaccine of animals previously vaccinated with an $S$ vaccine could be interesting since it would not booster antibody to the S-LPS which would interfere in serodiag- nosis. There are reports on RB51 use (reduced dose) after calfhood vaccination with S19 and data on the seroconversion in different tests (see Sect. 7.2.1) [89, 111, 127]. The degree of reinforcement of immunity achieved is not presently known.

A similar strategy would be the repeated use of an $\mathrm{R}$ vaccine. This practice has been implemented in northern Mexico where it is recommended to vaccinate calves at 5 months, to revaccinate 6 months later and to apply a third dose one year later. In case of abortions, revaccination is recommended [70]. According to a preliminary report, this practice, combined with infected herd management measures, has led to a reduction in prevalence from $30 \%$ to almost $0 \%$ in only three years [70]. Indeed, this is an unprecedented result in brucellosis eradication which calls for an urgent and detailed description of the observations, including 
Table IX. Comparison of vaccines $\mathrm{S} 19$ and $\operatorname{man}_{\text {core }}(r f b K) \mathrm{R}$ mutant against $B$. abortus in cattle ${ }^{1}$.

\begin{tabular}{lccc}
\hline Vaccine & Dose $(\mathrm{CFU})^{2}$ & No. of animals & No. infected (\%) \\
\hline manB $_{\text {core }}(r f b K)$ R mutant & $1 \times 10^{10}$ & 24 & $7(29)$ \\
S19 & $5 \times 10^{8}$ & 24 & $8(33)$ \\
Saline & & 25 & $25(100)$ \\
\hline
\end{tabular}

${ }^{1}$ Data are from Adams et al. [2]. The cows were challenged at 180 days of pregnancy with $1 \times 10^{7} \mathrm{CFU}$ of the virulent $B$. abortus 2308 strain given conjunctivally.

${ }^{2}$ Administered subcutaneously.

${ }^{3}$ Infection was defined by bacteriological isolation of the challenge strain from samples taken from mothers and calves.

management procedures, costs and possible side effects of the vaccine.

\subsection{B. abortus manB $B_{\text {core }}(r f b K)$ mutant}

This mutant was evaluated by Adams et al. [2] in controlled experiments in cattle in comparison with a reduced dose of S19 (Tab. IX). Both vaccines conferred significant protection against a heavy $B$. abortus challenge (all controls became infected). Moreover, even under these stringent conditions, there were no significant differences between the S19 vaccine and the $\mathrm{R}$ mutant. The RR values for the unvaccinated versus S19 and RB51 are practically identical (3.0 and 3.4 respectively $[P<$ $0.001])$ and differences between these vaccines are not significant $(P=0.3)$. On these basis, this $\mathrm{R}$ mutant seems to be a very promising vaccine. It has to be noted, however, that the report in which the experiments are described [2] does not contain a description of the bacteriological methods used to define infection and that this is necessary for a full appraisal of the results of this work. It is also interesting to note that a different $\mathrm{R}$ mutant in the same gene (B. abortus 55.30 man $_{\text {core }}$, see above) was not protective in the mouse model (see above) [78]. This could mean that Brucella vaccine studies in the mouse model are more limited than what it is generally thought, but also that other R mutants such as $w b k A$ and per may be either not attenuated enough or better $\mathrm{R}$ vaccines in cattle.

\section{R VACCINES TESTED IN SHEEP}

Sheep can be infected by B. melitensis or B. ovis and, in both cases, Rev 1 is the vaccine currently used $[16,17]$. The safety of RB51 in sheep has not been studied but there are two controlled studies in which the protective efficacy of RB51 and Rev 1 was compared. In one (Tab. X), young rams were vaccinated with either RB51 or Rev 1 and subjected to a severe $B$. ovis challenge [61]. Then, the development of the genital lesions characteristic of this infection were recorded, and a thorough bacteriological search for B. ovis was performed in thirteen organs and lymph nodes to evaluate both the protection and, in the infected rams, the severity of infection (see Tab. X for details). Under these stringent conditions, RB51 was neither able to protect the animals nor reduced the severity of the infection or the development of genital lesions. On the contrary, RR values (not shown) demonstrate statistically significant differences between Rev 1 and RB51 for protection $(P<0.05)$, and between Rev 1 and unvaccinated controls for both protection $(P<0.05)$ and severity of infection $(P<0.01)$. Moreover, El-Idrissi et al. [40] compared the ability of RB51 and Rev 1 to protect sheep against B. melitensis (Tab. XI). Even though the challenge was not as severe as in the B. ovis experiment $(77 \%$ of infection in the non vaccinated group), the performance of RB51 was poor. RR values (not shown) for the RB51 versus non vaccinated controls 
Table X. A comparison of vaccines RB51 and Rev 1 for their ability to protect rams against B. ovis ${ }^{1}$.

\begin{tabular}{lccccc}
\hline \multirow{2}{*}{ Vaccine } & No. of rams & Dose $(\mathrm{CFU})$ & \multicolumn{2}{c}{ No. infected $(\%)^{2}$} & \multirow{2}{*}{\begin{tabular}{c} 
No. with severe lesions \\
\cline { 3 - 4 }
\end{tabular}} \\
\cline { 4 - 5 } & & Total & Severely & \\
\hline Rev 1 & 16 & $1.1 \times 10^{9}$ & $11(69)$ & $7(69)$ & $6(38)$ \\
RB51 & 16 & $4.2 \times 10^{10}$ & $16(100)$ & $15(94)$ & $13(81)$ \\
None & 15 & & $15(100)$ & $15(100)$ & $9(60)$ \\
\hline
\end{tabular}

${ }^{1}$ Data are from Jiménez de Bagüés et al. [61]. Rams were vaccinated subcutaneously at 6 months of age and challenged 6 months later with $3 \times 10^{9} \mathrm{CFU}\left(1 \times 10^{9}\right.$ conjunctivally simultaneously with $1 \times 10^{9}$ preputially) of $B$. ovis PA.

2 Infection was defined by bacteriological isolation of the challenge strain (spleen, testes, epididymes, vesicular glands, bulbourethral glands, ampullae and seven lymph nodes were cultured). Rams that showed at least one necropsy sample infected with $\geq 125 \mathrm{CFU}$ of $B$. ovis were considered as severely infected.

${ }^{3}$ Severe lesions were edema, interstitial fibrosis, epithelial hyperplasia, and widespread infiltration of mononuclear and plasma cells.

Table XI. A comparison of vaccines RB51 and Rev 1 for their ability to protect sheep against B. melitensis ${ }^{1}$.

\begin{tabular}{lcccc}
\hline Vaccine & No. of ewes & Dose $(\mathrm{CFU})$ & No. infected $(\%)^{2}$ & No. of aborted animals $(\%)$ \\
\hline RB51 & 13 & $1.1 \times 10^{9}$ & $9(69)$ & $8(62)$ \\
Rev 1 & 14 & $1.7 \times 10^{8}$ & $2(14)$ & $1(7)$ \\
None & 13 & & $10(77)$ & $10(77)$ \\
\hline
\end{tabular}

${ }^{1}$ Data are from El-Idrissi et al [40]. Ewes were vaccinated subcutaneously and challenged at 2-3 months of gestation with $5 \times 10^{7} \mathrm{CFU}$ of virulent $B$. melitensis $\mathrm{H} 38$.

${ }_{2}^{2}$ Infection was defined by bacteriological isolation of the challenge strain (B. melitensis $\left.\mathrm{H} 38\right)$ from aborted fetuses and/or vaginal fluids.

are not significantly different $(P=0.67)$. On the contrary, there are highly significant differences in the RR values for the Rev 1 versus RB51 $(P<0.005)$, and Rev 1 versus non vaccinated $(P<0.001)$ comparisons. Similar conclusions are reached when the figures of aborted fetuses and/or perinatal deaths are analyzed.

\section{R VACCINES TESTED IN GOATS}

Three different $\mathrm{R}$ vaccines have been tested in goats: RB51, the $\operatorname{man}_{\text {core }}(r f b K)$ mutant which was also tested in cattle (see Sect. 7.3) and VTRM1. With regard to safety, it has been reported that RB51 and $m a n B_{\text {core }}(r f b K)$ are not shed in the milk of goats vaccinated with up to $4 \times 10^{10} \mathrm{CFU}$ [114] and there is preliminary evidence suggesting that they would not induce abortion at the same dose [121]. Moreover, there is one experiment in which three fetuses were directly inoculated "in utero" at 120 days of pregnancy with approximately $10^{7}$ to $10^{8} \mathrm{CFU}$ of RB51 without subsequent abortion, although vaginal excretion was observed in one doe [108]. In another study, the VTRM1 mutant did not cause abortion when inoculated into six goats at day 110 of pregnancy at a dose of $1 \times 10^{10} \mathrm{CFU}$ [42]. In both studies, 
Table XII. Summary of controlled experiments designed to evaluate R vaccines in goats.

\begin{tabular}{lccccc}
\hline $\begin{array}{l}\text { Experiment } \\
\text { [reference] }\end{array}$ & Vaccine & Dose (CFU) & No. of animals & Challenge $(\mathrm{CFU})^{2}$ & No. infected $(\%)^{3}$ \\
\hline $1[121]$ & RB51 & $4 \times 10^{10}$ & 15 & $9 \times 10^{5}$ & $1(7)$ \\
& ${\text { man } B_{\text {core }}(r f b k)}$ & $1 \times 10^{9}$ & 15 & $9 \times 10^{5}$ & $2(14)$ \\
$2[55]$ & Saline & & 10 & $9 \times 10^{5}$ & $6(60)$ \\
& RB51 & $1 \times 10^{9}$ & 6 & $2 \times 10^{7}$ & $2(33)$ \\
& Rev 1 & $1 \times 10^{10}$ & 10 & $2 \times 10^{7}$ & $1(10)$ \\
$3[42]$ & Saline & & 10 & $2 \times 10^{7}$ & $8(80)$ \\
& VTRM1 & $1 \times 10^{9}$ & 10 & $1 \times 10^{7}$ & $8(80)$ \\
& Rev 1 & $1 \times 10^{6}$ & 10 & $1 \times 10^{7}$ & $2(20)$ \\
& Saline & & 10 & $1 \times 10^{7}$ & $10(100)$ \\
\hline
\end{tabular}

1 Administered subcutaneously to adult animals.

2 The challenge was applied conjunctivally in all experiments. In Experiment 1, a B. melitensis biovar 1 field isolate was used and the animals challenged first at day 53 post vaccination and then at day 118 post vaccination, in both cases with the dose indicated in the Table. In Experiment 2, the animals were challenged with B. melitensis $\mathrm{H} 38$ three years after vaccination; and in Experiment 3, with B. melitensis 16M. All goats were conjunctivally challenged with $9 \times 10^{5} \mathrm{CFU}$ of a virulent $B$. melitensis strain.

${ }^{3}$ In all experiments, infection was defined by bacteriological isolation of the challenge strain (B. abortus 2308 in all cases). The organs cultured were: in Experiment 1, spleen, uterus, mammary gland and the most important lymph nodes; in Experiment 2, milk, uterus, mammary gland, spleen and lymph nodes; and in Experiment 3, spleen, liver and the most important lymph nodes.

however, the inoculations were performed during late pregnancy (see Sect. 7.2.2) so that no firm conclusions can be drawn on the abortive effect of the vaccine.

There are only preliminary reports on the protective effects of RB51 and $\operatorname{man} B_{\text {core }}$ $(r f b K)$ and they are summarized in Table XII. In Experiment 1 [121], RB51 and $m a n B_{\text {core }}(r f b K)$ afforded protection against a challenge that infected $60 \%$ of the unvaccinated goats (RR values of this control versus the vaccines were $9.0[P=0.006]$ and $4.5[P=0.028]$, respectively). It has to be noted, however, that the experimental protocol departs from others in that the animals had to be challenged twice before any became positive in standard serological tests (see footnotes of Tab. XII). This suggests that the first challenge was ineffective, and it cannot be ruled out that this first challenge may have had an immunizing effect against the second challenge. In Experiment 2 [55], RB51 was compared with Rev 1 . The number of animals in each group was different and very limited in some cases (Tab. XII). In contradiction with the results of Experiment 1, Rev 1 but not RB51 conferred significant protection in this experiment (RRs of $8.0[P=0.05]$ and $2.4[P=11]$, respectively, for the comparisons with the non vaccinated controls). Thus, it seems clear that additional work is necessary before solid conclusions could be reached on the value of RB51 or manB $B_{\text {core }}$ $(r f b K)$ for the prophylaxis of $B$. melitensis in goats. There is also a report on the usefulness of VTRM1 (like RB51 a wboA mutant) in goats [42]. When inoculated at $10^{10} \mathrm{CFU}$, VTMR1 persisted for two weeks in the organs of the animals but longer times were not studied. This vaccine does not confer protection against infection whereas Rev 1, even when used at very reduced doses, is effective (Tab. XII).

\section{0. $R$ VACCINES TESTED IN SWINE}

There have been numerous attempts to develop a vaccine against porcine brucellosis (reviewed in reference [6]) but so far none has been extensively used or clearly 
been proven useful and, under most circumstances, depopulation is the only procedure to control de disease. As an extension of the field experiments in cattle described above (see Sect. 7.2.4), RB51 has been used in swine [69]. In this study, sows were vaccinated with either RB51, a B. suis bacterin, or O-polysaccharide obtained from B. abortus $1119-3$ or B. suis 1330 by acid hydrolysis. The animals belonged to a farm with low seroprevalence (as judged by the standard serological tests) and, in addition to a possible accidental exposure, they were mated to infected boars. The follow-up consisted of serological testing (also using the conventional tests) and in a bacteriological examination of the abortions. According to these parameters, RB51 and the O-polysaccharides, but not the $B$. suis bacterin, afforded full protection, regardless of the dose $\left(10^{6}\right.$ to $10^{9} \mathrm{CFU}$, or 100 to $500 \mu \mathrm{g}$ of O-polysaccharide), the use of recall doses (up to 3 injections) and the route (intramuscular or oral). This total independence from route, dose and booster injections is remarkable and, as the authors pointed out, it is also noteworthy that two vaccines, live attenuated RB51 and O-polysaccharide, are similar in their protective capability despite the fact that they differ greatly in their composition. Indeed, the results with the O-polysaccharide are particularly intriguing since it is generally acknowledged that O-polysaccharides derived from S-LPS by acid hydrolysis behave as haptens and the $B$. suis bacterin, which carries immunogenic O-polysaccharide, was ineffective. Therefore, it seems that this set of remarkable observations needs to be substantiated in controlled experiments.

\section{R VACCINES AND WILDLIFE}

Brucella and/or antibodies to Brucella antigens have been detected in a large variety of mammal species, including many ungulates, lagomorphs, pinnipeds and cetaceans. A major issue with respect to wildlife brucellosis is whether the disease repre- sents an occasional event not sustainable in the absence of contact with the true hosts (as in humans) or, on the contrary, it is permanent [49]. In the second case, the disease may have been established for a long time (for example in marine mammals) or resulted from relatively recent contact with infected domestic livestock. When brucellosis is eradicated from the latter, susceptible wildlife may be a source of contagion and vaccination may be a necessary measure in areas where these animals come in contact with domestic livestock. There are vaccination studies performed in American bisons (Bison bison) and, to a lesser extent, in elks (Cervus elaphus). There are also data on the use of some Brucella vaccines in reindeer (Rangifer tarandus), pronghorn antelopes (Antilocapra americana), feral swine (Sus scrofa) and coyotes (Canis latrans). The reader is directed to the recent and complementary reviews by Davis and Elzer [30] and Godfroid [49] for a full appraisal of the problems and approaches involved, and only the main conclusions regarding the use of $\mathrm{R}$ vaccines in wildlife are summarized here.

Strain 19 is neither safe nor protective in the American bison [30]. Thus, RB51 has been tested in these animals but with contradictory results. With regard to safety, some authors report that RB51 causes both lesions similar to those produced by $\mathrm{S} 19$ [90] and abortion of pregnant female bisons [94]. Other studies do not substantiate these findings [30, 92] and, also based on some field observations, some authors conclude that RB51 is relatively safe in these animals [30]. Nevertheless, the protection afforded by RB51 seems nil in adult bisons and the studies performed in young female bisons are too limited to draw firm conclusions [30].

The elks of the Greater Yellowstone area often show antibodies to S Brucella, and $B$. abortus has been isolated in some cases [49]. In these animals, the situation has been created by artificial feeding during the winter, which increases the chances 
of contagion with other hosts coming to the same feeding grounds. The efficacy of S19 in elks is presently unknown [30] but there are studies on the protection provided by RB51. Controlled experiments in captive pregnant elks show that RB51, used either in reduced or full doses, does not protect against infection or abortion, even when booster vaccine doses are applied [26].

\section{CONCLUSION}

Among the different approaches to solve the problem of the interference of vaccination in the serodiagnosis of animal brucellosis, $\mathrm{R}$ vaccines represent an old but still interesting alternative that has not found either an optimal solution, nor a clear answer to its actual usefulness. Strain RB51 is stable and attenuated, but the evidence that it is equal or even better in terms of safety and efficacy than S19 is conflictive. In one field experiment subcutaneous vaccination of calves with reduced doses of RB51 is reported to afford absolute protection, no matter the prevalence, and to perform better than S19. Good protection is also reported in a controlled experiment in adult cattle vaccinated orally with (presumably) the full dose of RB51 but the bacteriological procedures used were not as complete as those of other studies. Moreover, absolute protection is reported in a controlled experiment in adult cattle vaccinated subcutaneously with the reduced dose of RB51. However, other controlled experiments showed that this same reduced dose and route is totally ineffective in calves. Because the evidence on the efficacy of the reduced dose of RB51 in adult cattle was obtained by challenging the animals at a time after vaccination shorter than that used in the experiments with calves, it seems that further experiments are necessary to test the duration of immunity afforded by the reduced dose. Other controlled experiments strongly suggest or prove that calfhood vaccination with the full dose of RB51 is only partially effective against moderate chal- lenges. This is also supported by the observational study under conditions of high prevalence presented here. Finally, depending upon the challenge, the available controlled comparative experiments show that S19 is a better vaccine than RB51. The evidence on the usefulness of RB51 in sheep and goats is either clearly negative or preliminary and contradictory, respectively. The possibilities of using RB51, or other $R$ vaccines, to booster immunity in adult animals vaccinated with the classical vaccines, or the use of repeated doses of an $\mathrm{R}$ vaccine deserve attention. However, evidence on the usefulness of these possible uses is not presently available.

In all these uses of RB51, it is also important to take into account the considerations made in the Introduction about the different contexts in which vaccination is applied, and the goals attainable. The desire of using a brucellosis $\mathrm{R}$ vaccine in countries that have very low prevalence or where control of brucellosis has been achieved and eradication is feasible, is understandable. However, at this point, the use of the RB51 vaccine is questionable in areas with moderate to high prevalence and where serological diagnosis is performed sporadically rather than on a regular basis, only in herds devoted to trade or because recurrent brucellosis is suspected. Under these conditions, which are commonly found in many low income countries, the use of well established and tested vaccines that have been demonstrated to be effective tools for the control and eradication of brucellosis for more than 60 years, must be preferred over vaccines that have not been thoroughly tested in comparative controlled experiments. Nobody doubts the benefits that a vaccine that avoids the conflict of differentiating vaccinated over infected animals will bring to all countries, but this serological discrimination must be balanced against protection, mainly in countries where serological diagnosis is not performed on a regular basis. 
Despite the lack of agreement among the experiments and the observations, and despite the possible shedding of rifampicin resistance genes into the environment, RB51 has been recently approved in the EU under the same conditions of use as in the US (it has to be noticed that cattle brucellosis was practically eradicated in the US by the time of licensing) and it is being used extensively in several Latin American countries instead of S19. Several million cattle have been vaccinated and, in some countries, S19 is not available anymore so that RB51 has become the obligatory vaccine [81]. However, there are no recorded results accessible to analysis which may substantiate claims on the benefits [70, 109, 113, 129] and not all these preliminary reports are favorable to RB51 [81]. A future assessment of the real effects of these massive vaccinations is likely to be controversial because of the complexity of the issues involved. They include not only the multiple ways in which the vaccine is being used (calfhood or adult vaccination, vaccine doses, one or several doses, the use of RB51 as a booster vaccine), often beyond the conditions of the original license (see Sect. 7.2.2), the effect of prevalence, the problems associated with delimiting the effects of the vaccine and of sanitary measures, or with obtaining reliable data in areas where breeding is extensive and official veterinary services scarce, but also political and economical interests. Brucellosis may seem to be a straightforward disease from a textbook but it is very complicated in the field and that is why conclusive controlled experiments should be mandatory before eradication enterprises are undertaken.

More recently developed $\mathrm{R}$ mutants may offer improved alternatives, including better protective efficacy and removal of the mutated genes and antibiotic markers. Although the evidence is limited to a single experiment in cattle, $B$. abortus manB $_{\text {core }}$ $(r f b K)$ seems promising. Other candidates, such as the $w b k A$ and per $\mathrm{R}$ mutants perform better than RB51 or manB $B_{\text {core }}(r f b K)$ in mice. This suggests that $R$ vaccines could be more efficient when the mutations involved in generating the $\mathrm{R}$ phenotype are such that the LPS core structure remains unscathed and carries no additional mutations elsewhere in the genome. The actual attenuation, safety and efficacy in the natural hosts of these mutants remain to be studied. A full understanding of the genetics and structure of the Brucella LPS, and of its precise role in the intracellular behavior of this pathogen, should provide a better basis for developing both better laboratory models and more effective vaccines.

\section{ACKNOWLEDGEMENTS}

We acknowledge Dr. Carlos Madriz assistance in field studies. D.M. and D.G. are recipients of a grant from Friends of the University of Navarra. We are also grateful to an anonymous reviewer for a thorough and constructive review and for drawing our attention to some aspects of the controlled experiments in cattle. Research at the laboratories of the authors is supported by the European Commission (Research Contracts QLK2-CT-2002-00918 and ICA4-CT-199910001), Ministerio de Ciencia y Tecnología of Spain (Proyecto AGL2000-0305-C02-01 and 02), Ministerio de Ciencia y Tecnología/Consejo Nacional de Ciencia y Tecnología (MICIT/ CONICIT) of Costa Rica, and by the program Redes Temáticas de Investigación Cooperativa FIS - Promoción de las Regiones (objectivo 2, 2000-2006, Red Temática de Investigación en Brucellosis. G03/204).

\section{REFERENCES}

[1] Adams L.G., Development of live Brucella vaccines, in: Adams L.G. (Ed.), Advances in brucellosis research, Texas A\&M University Press, College Station, 1990, pp. 250-276.

[2] Adams L.G., Ficht T.A., Allen C.A., Derivation and evaluation of the rough $r f b k$ brucellosis vaccine in cattle, in: Anonymous (Ed.), Memorias del III Foro Nacional de Brucelosis (20-21 July 1998), Acapulco, México, 1999, pp. 141-158.

[3] Allen C.A., Adams L.G., Ficht T.A., Transposon-derived Brucella abortus rough mutants are attenuated and exhibit reduced intracellular survival, Infect. Immun. 66 (1998) 1008-1016. 
[4] Alonso-Urmeneta B., Marín C.M., Aragón V., Blasco J.M., Díaz R., Moriyón I., Evaluation of lipopolysaccharides and polysaccharides of different epitopic structures in the indirect enzyme-linked immunosorbent assay for diagnosis of brucellosis in small ruminants and cattle, Clin. Diagn. Lab. Immunol. 5 (1998) 749-754.

[5] Alton G.G., Experiences with Brucella vaccines, in: Crawford R.M., Hidalgo R.J. (Eds.), Bovine brucellosis. An international Symposium, Texas A\&M University Press, College Station, 1977, pp. 209-217.

[6] Alton G.G., Brucella suis, in: Nielsen K.H., Duncan J.R. (Eds.), Animal Brucellosis, CRC Press, Boca Raton, 1990, pp. 411-422.

[7] Alton G.G., Elberg S.S., Rev. 1 Brucella melitensis vaccine: A review of ten years of study, Vet. Bull. 371 (1967) 793-800.

[8] Alton G.G., Corner L.A., Plackett P., Vaccination against bovine brucellosis, Dev. Biol. Stand. 56 (1984) 643-647.

[9] Alton G.G., Jones L.M., Angus R.D., Verger J.M., Techniques for the brucellosis laboratory, INRA, Paris, France, 1988.

[10] Anonymous, Manual of Standards for Diagnostic Tests and Vaccines, Office International des Epizooties, Paris, France, 2001.

[11] Anonymous, Vaccin vivant cryodesseche de la brucellose (Brucella melitensis Rev 1) pour usage veterinaire, in: Conseil de l'Europe (Ed.), Pharmacopee Europeenne, 2001.

[12] Aragón V., Díaz R., Moreno E., Moriyón I., Characterization of Brucella abortus and Brucella melitensis native haptens as outer membrane O-type polysaccharides independent from the smooth lipopolysaccharide, J. Bacteriol. 178 (1996) 1070-1079.

[13] Ariza J., Brucellosis: an update. The perspective from the Mediterranean basin, Rev. Med. Microbiol. 10 (1999) 125-135.

[14] Bagnat E., Maneti J.C., Prueba de eficacia de las vacunas antibrucélicas RB51 y cepa 19 en bovinos, Rev. Med. Vet. 81 (2002) 428-429.

[15] Bagnat E., Maneti J.C., Prueba de eficacia (potencia) de las vacunas antibrucélicas RB51 y cepa 19, en bovinos, Documento interno, SENASA, 2003.

[16] Blasco J.M., Brucella ovis, in: Nielsen K.H., Duncan J.R. (Eds.), Animal Brucellosis, CRC Press, Boca Raton, 1990, pp. 352-378.

[17] Blasco J.M., A review of the use of $B$. melitensis Rev 1 vaccine in adult sheep and goats, Prev. Vet. Med. 31 (1997) 275-283.

[18] Bosseray N., Brucella melitensis Rev. 1 living attenuated vaccine: stability of markers, residual virulence and immunogenicity in mice, Biologicals 19 (1991) 355-363.
[19] Briones G.C., Iñón de Iannino N., Roset M., Vigliocco A.M., Paulo P.S., Ugalde R.A., Brucella abortus cyclic beta-1,2-glucan mutants have reduced virulence in mice and are defective in intracellular replication in HeLa cells, Infect. Immun. 69 (2001) 45284535.

[20] Cheville N.F., Jensen A.E., Halling S.M., Tatum F.M., Morfitt D.C., Hennager S.G., Frerichs W.M., Schurig G.G., Bacterial survival, lymph node changes, and immunologic responses of cattle vaccinated with standard and mutant strains of Brucella abortus, Am. J. Vet. Res. 53 (1992) 1881-1888.

[21] Cheville N.F., Stevens M.G., Jensen A.E., Tatum F.M., Halling S.M., Immune responses and protection against infection and abortion in cattle experimentally vaccinated with mutant strains of Brucella abortus, Am. J. Vet. Res. 54 (1993) 1591-1597.

[22] Cheville N.F., Olsen S.C., Jensen A.E., Stevens M.G., Palmer M.V., Florance A.M., Effects of age at vaccination on efficacy of Brucella abortus strain RB51 to protect cattle against brucellosis, Am. J. Vet. Res. 57 (1996) 1153-1156.

[23] Ciuchini F., Adone R., Pasquali P., Coombs antiglobulin test using Brucella abortus 99 as antigen to detect incomplete antibodies induced by B. abortus RB51 vaccine in cattle, Clin. Diagn. Lab. Immunol. 9 (2002) 13981399.

[24] Cloeckaert A., Weynants V.E., Godfroid J., Verger J.M., Grayon M., Zygmunt M.S., OPolysaccharide epitopic heterogeneity at the surface of Brucella spp. studied by enzymelinked immunosorbent assay and flow cytometry, Clin. Diagn. Lab. Immunol. 5 (1998) 862-870.

[25] Cloeckaert A., Zygmunt M.S., Guilloteau L.A., Brucella abortus vaccine strain RB51 produces low levels of M-like O-antigen, Vaccine 20 (2002) 1820-1822.

[26] Cook W.E., Williams E.S., Thorne E.T., Kreeger T.J., Stout G., Bardsley K., Edwards H., Schurig G., Colby L.A., Enright F., Elzer P.H., Brucella abortus strain RB51 vaccination in elk. I. Efficacy of reduced dosage, J. Wildl. Dis. 38 (2002) 18-26.

[27] Corbeil L.B., Blau K., Inzana T.J., Nielsen K.H., Jacobson R.H., Corbeil R.R., Winter A.J., Killing of Brucella abortus by bovine serum, Infect. Immun. 56 (1988) 3251-3261.

[28] Crawford R.M., Hidalgo R.J., Immunization discussion, in: Crawford R.M., Hidalgo R.J. (Eds.), Bovine brucellosis. An international Symposium, Texas A\&M University Press, College Station, 1977, pp. 218-265.

[29] Cunningham B., A difficult disease called brucellosis, in: Crawford R.M., Hidalgo R.J. (Eds.), Bovine brucellosis. An international 
Symposium, Texas A\&M University Press, College Station, 1977, pp. 11-20.

[30] Davis D.S., Elzer P.H., Brucella vaccines in wildlife, Vet. Microbiol. 90 (2002) 533-544.

[31] DelVecchio V.G., Kapatral V., Redkar R.J., Patra G., Mujer C., Los T., Ivanova N., Anderson I., Bhattacharyya A., Lykidis A., Reznik G., Jablonski L., Larsen N., D’Souza M., Bernal A., Mazur M., Goltsman E., Selkov E., Elzer P., Hagius S., O'Callaghan D., Letesson J.J., Haselkorn R., Kyrpides N., Overbeek R., The genome sequence of the facultative intracellular pathogen Brucella melitensis, Proc. Natl. Acad. Sci. USA 99 (2002) 443-448.

[32] Detilleux P.G., Deyoe B.L., Cheville N.F., Entry and intracellular localization of $\mathrm{Bru}$ cella spp. in Vero cells: fluorescence and electron microscopy, Vet. Pathol. 27 (1990) 317-328.

[33] Díaz R., Garatea P., Jones L.M., Moriyón I., Radial immunodiffusion test with a Brucella polysaccharide antigen for differentiating infected from vaccinated cattle, J. Clin. Microbiol. 10 (1979) 37-41.

[34] Díaz R., Toyos J., Salvo M.D., Pardo M.L., A simple method for the extraction of polysaccharide B from Brucella cells for use in the radial immunodiffusion test diagnosis of bovine brucellosis, Ann. Rech. Vet. 12 (1981) 35-39.

[35] Díaz-Aparicio E., Aragón V., Marín C.M., Alonso-Urmeneta B., Font M., Moreno E., Pérez-Gómez S., Blasco J.M., Díaz R., Moriyón I., Comparative analysis of Brucella serotype $\mathrm{A}$ and $\mathrm{M}$ and Yersinia enterocolitica O: 9 polysaccharides for serological diagnosis of brucellosis in cattle, sheep, and goats, J. Clin. Microbiol. 31 (1993) 3136-3141.

[36] Díaz-Aparicio E., Marín C.M., AlonsoUrmeneta B., Aragón V., Pérez-Gómez S., Pardo M.L., Blasco J.M., Díaz R., Moriyón I., Evaluation of serological tests for diagnosis of Brucella melitensis infection of goats, J. Clin. Microbiol. 32 (1994) 1159-1165.

[37] Douglas J.T., Palmer D.A., Use of monoclonal antibodies to identify the distribution of $\mathrm{A}$ and $\mathrm{M}$ epitopes on smooth Brucella species, J. Clin. Microbiol. 26 (1988) 13531356.

[38] Edmonds M.D., Cloeckaert A., Elzer P.H., Brucella species lacking the major outer membrane protein Omp25 are attenuated in mice and protect against Brucella melitensis and Brucella ovis, Vet. Microbiol. 88 (2002) 205-221.

[39] Edmonds M.D., Schurig G.G., Samartino L.E., Hoyt P.G., Walker J.V., Hagius S.D., Elzer P.H., Biosafety of Brucella abortus strain RB51 for vaccination of mature bulls and pregnant heifers, Am. J. Vet. Res. 60 (1999) 722-725.

[40] El-Idrissi A.H., Benkirane A., El-Maadoudi M., Bouslikhane M., Berrada J., Zerouali A., Comparison of the efficacy of Brucella abortus strain RB51 and Brucella melitensis Rev. 1 live vaccines against experimental infection with Brucella melitensis in pregnant ewes, Rev. Sci Tech. Off. Int. Epizoot. 20 (2001) 741-747.

[41] Elzer P.H., Enright F.M., Colby L., Hagius S.D., Walker J.V., Fatemi M.B., Kopec J.D., Beal V.C., Schurig G.G., Protection against infection and abortion induced by virulent challenge exposure after oral vaccination of cattle with Brucella abortus strain RB51, Am. J. Vet. Res. 59 (1998) 1575-1578.

[42] Elzer P.H., Enright F.M., McQuiston J.R., Boyle S.M., Schurig G.G., Evaluation of a rough mutant of Brucella melitensis in pregnant goats, Res. Vet. Sci. 64 (1998) 259-260.

[43] Fensterbank R., Plommet M., Vaccination against bovine brucellosis with a low dose of strain 19 administered by the conjunctival route. IV. Comparison between two methods of vaccination, Ann. Rech. Vet. 10 (1979) 131-139.

[44] Fernandez-Prada C.M., Nikolich M., Vemulapalli R., Sriranganathan N.M., Boyle S.M., Schurig G.G., Hadfield T.L., Hoover D.L., Deletion of $w b o A$ enhances activation of the lectin pathway of complement in $\mathrm{Bru}$ cella abortus and Brucella melitensis, Infect. Immun. 69 (2001) 4407-4416.

[45] Folch H., Rojas X., Oñate A.A., Alonso O., Leynan V., Jara U., Humoral and cellular responses in calves vaccinated with Brucella abortus RB51, Arch. Med. Vet. 95 (1995) 125-130.

[46] Foulongne V., Bourg G., Cazevieille C., Michaux-Charachon S., O'Callaghan D., Identification of Brucella suis genes affecting intracellular survival in an in vitro human macrophage infection model by signaturetagged transposon mutagenesis, Infect. Immun. 68 (2000) 1297-1303.

[47] Freer E., Moreno E., Moriyón I., PizarroCerdá J., Weintraub A., Gorvel J.P., BrucellaSalmonella lipopolysaccharide chimeras are less permeable to hydrophobic probes and more sensitive to cationic peptides and EDTA than are their native Brucella sp. counterparts, J. Bacteriol. 178 (1996) 5867-5876.

[48] Freer E., Pizarro-Cerdá J., Weintraub A., Bengoechea J.A., Moriyón I., Hultenby K., Gorvel J.P., Moreno E., The outer membrane of Brucella ovis shows increased permeability to hydrophobic probes and is more susceptible to cationic peptides than are the outer membranes of mutant rough Brucella abortus strains, Infect. Immun. 67 (1999) 6181-6186. 
[49] Godfroid J., Brucellosis in wildlife, Rev. Sci. Tech. Off. Int. Epizoot. 21 (2002) 277-286.

[50] Godfroid F., Taminiau B., Danese I., Denoel P.A., Tibor A., Weynants V.E., Cloeckaert A., Godfroid J., Letesson J.J., Identification of the perosamine synthetase gene of Brucella melitensis $16 \mathrm{M}$ and involvement of lipopolysaccharide $\mathrm{O}$ side chain in Brucella survival in mice and in macrophages, Infect. Immun. 66 (1998) 5485-5493.

[51] Godfroid F., Cloeckaert A., Taminiau B., Danese I., Tibor A., de Bolle X., Mertens P., Letesson J.J., Genetic organisation of the lipopolysaccharide O-antigen biosynthesis region of Brucella melitensis 16M (wbk), Res. Microbiol. 151 (2000) 655-668.

[52] Grilló M.J., Bosseray N., Blasco J.M., In vitro markers and biological activity in mice of seed lot strains and commercial Brucella melitensis Rev 1 and Brucella abortus B19 vaccines, Biologicals 28 (2000) 119-127.

[53] Hamdy M.-E.R., El-Gibaly S.M., Montasser A.M., Comparison between immune responses and resistance induced in $\mathrm{BALB} / \mathrm{c}$ mice vaccinated with RB51 and Rev. 1 vaccines and challenged with Brucella melitensis bv. 3, Vet. Microbiol. 88 (2002) 85-94.

[54] Heinrichs D.E., Valvano M.A., Whitfield C., Biosynthesis and genetics of the lipopolysaccharide core, in: Brade H., Opal S.M., Vogel S.N., Morrison D.C. (Eds.), Endotoxin in health and disease, Marcel Dekker, New York, 1999, pp. 305-358.

[55] Hernández L., Ochoa D., Díaz E., Córdoba L., López M., Ontiveros C., Conferred protection for RB51 vaccine in goats, 54th Annual Brucellosis Research Conference. Nov 10-11. St Louis, 2001.

[56] Huber J.D., Beal V.C., Crawford R.P., Adams L.G., An evaluation of reduced dose Brucella abortus strain 19 vaccination, in: Adams L.G. (Ed.), Advances in brucellosis research, Texas A\&M University Press, College Station, 1990, pp. 228-249.

[57] Iñón de Iannino N., Briones G.C., Tolmasky M., Ugalde R.A., Molecular cloning and characterization of cgs, the Brucella abortus cyclic beta(1-2) glucan synthetase gene: genetic complementation of Rhizobium meliloti $n d v B$ and Agrobacterium tumefaciens $\operatorname{chvB}$ mutants, J. Bacteriol. 180 (1998) 4392-4400.

[58] Jacques I., Cloeckaert A., Limet J.N., Dubray G., Protection conferred on mice by combinations of monoclonal antibodies directed against outer-membrane proteins or smooth lipopolysaccharide of Brucella, J. Med. Microbiol. 37 (1992) 100-103.

[59] Jiménez de Bagüés M.P., Marín C.M., Blasco J.M., Effect of antibiotic therapy and strain-19 vaccination on the spread of Bru- cella melitensis within an infected dairy herd, Prev. Vet. Med. 11 (1991) 17-24.

[60] Jiménez de Bagüés M.P., Elzer P.H., Jones S.M., Blasco J.M., Enright F.M., Schurig G.G., Winter A.J., Vaccination with Brucella abortus rough mutant RB51 protects BALB/ c mice against virulent strains of Brucella abortus, Brucella melitensis, and Brucella ovis, Infect. Immun. 62 (1994) 4990-4996.

[61] Jiménez de Bagüés M.P., Barberán M., Marín C.M., Blasco J.M., The Brucella abortus RB51 vaccine does not confer protection against Brucella ovis in rams, Vaccine 13 (1995) 301-304.

[62] Jones L.M., Berman D.T., Antibody response, delayed type hypersensitivity and immunity in guinea pigs induced by smooth and rough strains of Brucella abortus, J. Infect. Dis. 124 (1975) 47-57.

[63] Jones L.M., Berman D.T., Moreno E., Deyoe B.L., Gilsdorf M.J., Huber J.D., Nicoletti P.L., Evaluation of a radial immunodiffusion test with polysaccharide B antigen for diagnosis of bovine brucellosis, J. Clin. Microbiol. 12 (1980) 753-760.

[64] Keenleyside W.J., Whitfield C., Genetics and biosynthesis of lipopolysaccharide O-antigens, in: Brade H., Opal S.M., Vogel S.N., Morrison D.C. (Eds.), Endotoxin in health and disease, Marcel Dekker, New York, 1999, pp. 331-358.

[65] Kreeger T.J., DeLiberto T.J., Olsen S.C., Edwards W.H., Cook W.E., Safety of Brucella abortus strain RB51 vaccine in non-target ungulates and coyotes, J. Wildl. Dis. 38 (2002) 552-557.

[66] Lopetegui P., Erradicación de brucelosis bovina en Chile. Experiencias en el uso de la vacuna cepa RB51, in: Luna-Martinez E., Suarez-Guemes F. (Eds.), III Foro Nacional de brucelosis, Acapulco, Mexico, 20-21 July, Anonymous, 1998, pp. 159-179.

[67] Lord V.R., Rolo M.R., Cherwonogrodzky J.W., Evaluation of humoral immunity to Brucella sp in cattle by use of an agar-gel immunodiffusion test containing a polysaccharide antigen, Am. J. Vet. Res. 50 (1989) 18131816.

[68] Lord V.R., Schurig G.G., Cherwonogrodzky J.W., Marcano M.J., Melendez G.E., Field study of vaccination of cattle with Brucella abortus strains RB51 and 19 under high and low disease prevalence, Am. J. Vet. Res. 59 (1998) 1016-1020.

[69] Lord V.R., Cherwonogrodzky J.W., Schurig G.G., Lord R.D., Marcano M.J., Melendez G.E., Venezuelan field trials of vaccines against brucellosis in swine, Am. J. Vet. Res. 59 (1998) 546-551. 
[70] Luna-Martinez J.E., Mejia-Teran C., Brucellosis in Mexico: current status and trends, Vet. Microbiol. 90 (2002) 19-30.

[71] MacMillan A.P., Conventional serological tests, in: Nielsen K.H., Duncan J.R. (Eds.), Animal Brucellosis, CRC Press, Boca Raton, 1990, pp. 153-197.

[72] Marín C.M., Moreno E., Moriyón I., Díaz R., Blasco J.M., Performance of competitive and indirect enzyme-linked immunosorbent assays, gel immunoprecipitation with native hapten polysaccharide, and standard serological tests in diagnosis of sheep brucellosis, Clin. Diagn. Lab. Immunol. 6 (1999) 269-272.

[73] Martin S.W., Meek A.H., Willeberg P., Veterinary Epidemiology. Principles and Methods, Iowa State University Press, Ames, Iowa, 1987.

[74] Martinez de Tejada G., Pizarro-Cerdá J., Moreno E., Moriyón I., The outer membranes of Brucella spp. are resistant to bactericidal cationic peptides, Infect. Immun. 63 (1995) 3054-3061.

[75] McEwen A.D., Experiments on contagious abortion. Immunization studies with vaccines of graded virulence, Vet. Rec. 50 (1938) 1097-2002.

[76] McQuiston J.R., Vemulapalli R., Inzana T.J., Schurig G.G., Sriranganathan N.M., Fritzinger D., Hadfield T.L., Warren R.A., Snellings N., Hoover D.L., Halling S.M., Boyle S.M., Genetic characterization of a Tn5-disrupted glycosyltransferase gene homologue in Brucella abortus and its effect on lipopolysaccharide composition and virulence, Infect. Immun. 67 (1999) 3830-3835.

[77] Meyer M.E., Characterization of Brucella abortus strain 19 isolated from human and bovine tissues and fluids, Am. J. Vet. Res. 46 (1985) 902-904.

[78] Monreal D., Grillo M.J., Gonzalez D., Marin C.M., de Miguel M.J., Lopez-Goni I., Blasco J.M., Cloeckaert A., Moriyon I., Characterization of Brucella abortus O-Polysaccharide and core lipopolysaccharide mutants and demonstration that a complete core is required for rough vaccines to be efficient against Brucella abortus and Brucella ovis in the mouse model, Infect. Immun. 71 (2003) 3261-3271.

[79] Montaraz J.A., Winter A.J., Comparison of living and nonliving vaccines for Brucella abortus in BALB/c mice, Infect. Immun. 53 (1986) 245-251.

[80] Montaraz J.A., Winter A.J., Hunter D.M., Sowa B.A., Wu A.M., Adams L.G., Protection against Brucella abortus in mice with O-polysaccharide-specific monoclonal antibodies, Infect. Immun. 51 (1986) 961-963.

[81] Moreno E., Brucellosis in Central America, Vet. Microbiol. 90 (2002) 31-38.
[82] Moriyón I., Gamazo C., Díaz R., Properties of the outer membrane of Brucella, Ann. Inst. Pasteur Microbiol. 138 (1987) 89-91.

[83] Mustafa A.A., Abusowa M., Field-oriented trial of the Chinese Brucella suis strain 2 vaccine on sheep and goats in Libya, Vet. Res. 24 (1993) 422-429.

[84] Nicoletti P.L., Vaccination, in: Nielsen K.H., Duncan J.R. (Eds.), Animal Brucellosis, CRC Press, Boca Raton, 1990, pp. 283-299.

[85] Nielsen K., Diagnosis of brucellosis by serology, Vet. Microbiol. 90 (2002) 447-459.

[86] Olsen S., Palmer M.V., Stevens M.G., La nueva vacuna contra la brucelosis no causa falsos positivos, Hoard's Dairyman (Spanish edition), February issue, 1997, pp. 90-91.

[87] Olsen S.C., Immune responses and efficacy after administration of a commercial Brucella abortus RB51 vaccine to cattle, Vet. Ther. 3 (2000) 183-191.

[88] Olsen S.C., Responses of adult cattle to vaccination with a reduced dose of Brucella abortus strain RB51, Res. Vet. Sci. 69 (2000) 135-140.

[89] Olsen S.C., Evans D., Hennager S.G., Cheville N.F., Stevens M.G., Serologic responses of Brucella abortus strain 19 calfhood-vaccinated cattle following adult vaccination with strain RB51, J. Vet. Diagn. Invest. 8 (1996) 451-454.

[90] Olsen S.C., Cheville N.F., Kunkle R.A., Palmer M.V., Jensen A.E., Bacterial survival, lymph node pathology, and serological responses of bison (Bison bison) vaccinated with Brucella abortus strain RB51 or strain 19, J. Wildl. Dis. 33 (1997) 146-151.

[91] Olsen S.C., Bricker B.J., Palmer M.V., Jensen A.E., Cheville N.F., Responses of cattle to two dosages of Brucella abortus strain RB51: serology, clearance and efficacy, Res. Vet. Sci. 66 (1999) 101-105.

[92] Olsen S.C., Rhyan J.C., Gidlewski T., Palmer M.V., Jones A.H., Biosafety and antibody responses of adult bison bulls after vaccination with Brucella abortus strain RB51, Am. J. Vet. Res. 60 (1999) 905-908.

[93] Palmer M.V., Cheville N.F., Jensen A.E., Experimental infection of pregnant cattle with the vaccine candidate Brucella abortus strain RB51: pathologic, bacteriologic, and serologic findings, Vet. Pathol. 33 (1996) 682691.

[94] Palmer M.V., Olsen S.C., Gilsdorf M.J., Philo L.M., Clarke P.R., Cheville N.F., Abortion and placentitis in pregnant bison (Bison bison) induced by the vaccine candidate, $\mathrm{Bru}$ cella abortus strain RB51, Am. J. Vet. Res. 57 (1996) 1604-1607. 
[95] Palmer M.V., Olsen S.C., Cheville N.F., Safety and immunogenicity of Brucella abortus strain RB51 vaccine in pregnant cattle, Am. J. Vet. Res. 58 (1997) 472-477.

[96] Paulsen I.T., Seshadri R., Nelson K.E., Eisen J.A., Heidelberg J.F., Read T.D., Dodson R.J., Umayam L., Brinkac L.M., Beanan M.J., Daugherty S.C., Deboy R.T., Durkin A.S., Kolonay J.F., Madupu R., Nelson W.C., Ayodeji B., Kraul M., Shetty J., Malek J., Van-Aken S.E., Riedmuller S., Tettelin H., Gill S.R., White O., Salzberg S.L., Hoover D.L., Lindler L.E., Halling S.M., Boyle S.M., Fraser C.M., The Brucella suis genome reveals fundamental similarities between animal and plant pathogens and symbionts, Proc. Natl. Acad. Sci. USA 99 (2002) 13148-13153.

[97] Perry M.B., Bundle D.R., Lipopolysaccharide antigens and carbohydrates of Brucella, in: Adams L.G. (Ed.), Advances in brucellosis research, Texas A\&M University Press, College Station, 1990, pp. 76-88.

[98] Pizarro-Cerdá J., Meresse S., Parton R.G., Van der Goot G., Sola-Landa A., LópezGoñi I., Moreno E., Gorvel J.P., Brucella abortus transits through the autophagic pathway and replicates in the endoplasmic reticulum of nonprofessional phagocytes, Infect. Immun. 66 (1998) 5711-5724.

[99] Pizarro-Cerdá J., Moreno E., Gorvel J.P., Brucella abortus invasion and survival within professional and nonprofessional phagocytes, Adv. Cell Mol. Biol. Membr. Org. 6 (1999) 201-232.

[100] Plommet M., Fensterbank R., La vaccination antibrucellique administree par voie conjonctivale, Dev. Biol. Stand. 56 (1984) 681-687.

[101] Plommet M., Plommet A.M., Immune serummediated effects on brucellosis evolution in mice, Infect. Immun. 41 (1983) 97-105.

[102] Plommet M., Renoux G., Philippon A., Gestin J., Fensterbank R., Transmission congenitale de la brucellose bovine d'une génération à l'autre, Bull. Acad. Vet. Fr. 44 (1971) 53-59.

[103] Qureshi N., Takayama K., Seydel U., Wang R., Cotter R.J., Agrawal P.K., Bush C.A., Kurtz R.S., Berman D.T., Structural analysis of the lipid A from the lipopolysaccharide of Brucella abortus, J. Endotoxin Res. 1 (1994) 137-148.

[104] Reeves P.R., Hobbs M., Valvano M.A., Skurnik M., Whitfield C., Coplin D., Kido N., Klena J., Maskell D., Raetz C.R., Rick P.D., Bacterial polysaccharide synthesis and gene nomenclature, Trends Microbiol. 4 (1996) 495-503.
[105] Riley L.K., Robertson D.C., Brucellacidal activity of human and bovine polymorphonuclear leukocyte granule extracts against smooth and rough strains of Brucella abortus, Infect. Immun. 46 (1984) 231-236.

[106] Roerink J.H., Experience on the safety and effectiveness of 45-20 vaccine under field conditions, Vet. Rec. 85 (1969) 269-270.

[107] Rojas N., Freer E., Weintraub A., Ramirez M., Lind S., Moreno E., Immunochemical identification of Brucella abortus lipopolysaccharide epitopes, Clin. Diagn. Lab. Immunol. 1 (1994) 206-213.

[108] Roop R.M., Jeffers G., Bagchi T., Walker J., Enright F.M., Schurig G.G., Experimental infection of goat fetuses in utero with a stable, rough mutant of Brucella abortus, Res. Vet. Sci. 51 (1991) 123-127.

[109] Samartino L.E., Brucellosis in Argentina, Vet. Microbiol. 90 (2002) 71-80.

[110] Samartino L.E., Enright F.M., Interaction of bovine chorioallantoic membrane explants with three strains of Brucella abortus, Am. J. Vet. Res. 53 (1992) 359-363.

[111] Samartino L.E., Fort M., Gregoret R., Schurig G.G., Use of Brucella abortus vaccine strain RB51 in pregnant cows after calfhood vaccination with strain 19 in Argentina, Prev. Vet. Med. 45 (2000) 193-199.

[112] Schurig G.G., Roop R.M., Bagchi T., Boyle S., Buhrman D., Sriranganathan N.M., Biological properties of RB51; a stable rough strain of Brucella abortus, Vet. Microbiol. 28 (1991) 171-188

[113] Schurig G.G., Sriranganathan N., Corbel M.J., Brucellosis vaccines: past, present and future, Vet. Microbiol. 90 (2002) 479-496.

[114] Soberon-Mobarak A., Díaz-Aparicio E., Torres-Armenta J., Adams L.G., SuarezGuemes F., Absence of shedding of two $B$. abortus strains in goats after vaccination with live vaccines, Vaccine 18 (2000) 3018-3020.

[115] Sola-Landa A., Pizarro-Cerdá J., Grilló M.J., Moreno E., Moriyón I., Blasco J.M., Gorvel J.P., López-Goñi I., A two-component regulatory system playing a critical role in plant pathogens and endosymbionts is present in Brucella abortus and controls cell invasion and virulence, Mol. Microbiol. 29 (1998) 125-138.

[116] Spink W.W., The nature of brucellosis. Chapter 2, The Brucella cell, Lund Press Inc., Minneapolis, 1956.

[117] Stevens M.G., Olsen S.C., Antibody responses to Brucella abortus 2308 in cattle vaccinated with $B$. abortus RB51, Infect. Immun. 64 (1996) 1030-1034. 
[118] Stevens M.G., Hennager S.G., Olsen S.C., Cheville N.F., Serologic responses in diagnostic tests for brucellosis in cattle vaccinated with Brucella abortus 19 or RB51, J. Clin. Microbiol. 32 (1994) 1065-1066.

[119] Stevens M.G., Olsen S.C., Cheville N.F., Comparative analysis of immune responses in cattle vaccinated with Brucella abortus strain 19 or strain RB51, Vet. Immunol. Immunopathol. 44 (1995) 223-235.

[120] Stevens M.G., Olsen S.C., Pugh G.W., Brees D., Comparison of immune responses and resistance to brucellosis in mice vaccinated with Brucella abortus 19 or RB51, Infect. Immun. 63 (1995) 264-270.

[121] Suarez-Guemes F., Soberon-Mobarak A., Díaz-Aparicio E., Adams L.G., Evaluación de la vacuna RB51 y la vacuna experimental $r f b K$ para su uso en caprinos, in: Anonymous (Ed.), Memorias del III Foro Nacional de Brucelosis (20-21 July 1998), Acapulco, México, 1999, pp. 191-204.

[122] Sulitzeanu D., Jones L.M., Stableforth A.W., Protective action of monospecific anti- $\mathrm{Bru}$ cella sera in mice, Nature 175 (1955) 1040 1041.

[123] Sutherland S.S., Searson J., The immune response to Brucella abortus: the humoral response, in: Nielsen K.H., Duncan J.R. (Eds.), Animal Brucellosis, CRC Press, Boca Raton, 1990, pp. 65-81.

[124] Sutherland S.S., Robertson A.G., Le Cras D.V., Robertson G.M., Johnston J.M., Evans R.J., The effect of challenge with virulent Brucella abortus on beef cattle vaccinated as calves or adults with either Brucella abortus strain 19 or 45/20, Aust. Vet. J. 57 (1981) 470-473.

[125] Taylor A.W., McDiamird A., The stability of the avirulent characters of Brucella abortus strain 19 and strain 45/20 in lactating and pregnant cows, Vet. Rec. 61 (1949) 317318.

[126] Ugalde J.E., Czibener C., Feldman M.F., Ugalde R.A., Identification and characterization of the Brucella abortus phosphoglucomutase gene: role of lipopolysaccharide in virulence and intracellular multiplication, Infect. Immun. 68 (2000) 5716-5723.

[127] Uzal F.A., Samartino L.E., Schurig G.G., Carrasco A., Nielsen K.H., Cabrera R.F., Taddeo H.R., Effect of vaccination with Brucella abortus strain RB51 on heifers and pregnant cattle, Vet. Res. Commun. 24 (2000) 143-151.

[128] Van Metre D.C., Kennedy G.A., Olsen S.C., Hansen G.R., Ewalt D.R., Brucellosis induced by RB51 vaccine in a pregnant heifer, J. Am. Vet. Med. Assoc. 215 (1999) 1491-1493.

[129] Vargas O., Brucellosis in Venezuela, Vet. Microbiol. 90 (2002) 39-44.

[130] Velasco J., Bengoechea J.A., Brandenburg K., Lindner B., Seydel U., González D., Zähringer U., Moreno E., Moriyón I., Brucella abortus and its closest phylogenetic relative, Ochrobactrum spp., differ in outer membrane permeability and cationic peptide resistance, Infect. Immun. 68 (2000) 3210 3218.

[131] Vemulapalli R., McQuiston J.R., Schurig G.G., Sriranganathan N.M., Halling S.M., Boyle S.M., Identification of and IS711 element interrupting the wboA gene of Brucella abortus vaccine strain RB51 and a PCR assay to distinguish strain RB51 from other Brucella species and strains, Clin. Diagn. Lab. Immunol. 6 (1999) 760-764.

[132] Vemulapalli R., He Y., Buccolo L.S., Boyle S.M., Sriranganathan N.M., Schurig G.G., Complementation of Brucella abortus RB51 with a functional $w b o A$ gene results in $\mathrm{O}$ antigen synthesis and enhanced vaccine efficacy but no change in rough phenotype and attenuation, Infect. Immun. 68 (2000) 3927 3932.

[133] Vemulapalli R., He Y., Cravero S., Sriranganathan N.M., Boyle S.M., Schurig G.G., Overexpression of protective antigen as a novel approach to enhance vaccine efficacy of Brucella abortus strain RB51, Infect. Immun. 68 (2000) 3286-3289.

[134] Villarroel M., Grell M., Saenz R., Reporte de primer caso humano de aislamiento y tipificación de Brucella abortus RB51, Arch. Med. Vet. 32 (2000) 89-91.

[135] Winter A.J., Schurig G.G., Boyle S.M., Sriranganathan N.M., Bevins J.S., Enright F.M., Elzer P.H., Kopec J.D., Protection of $\mathrm{BALB} / \mathrm{c}$ mice against homologous and heterologous species of Brucella by rough strain vaccines derived from Brucella melitensis and Brucella suis biovar 4, Am. J. Vet. Res. 57 (1996) 677-683.

[136] Xin X., Orally administrable brucellosis vaccine: Brucella suis strain 2 vaccine, Vaccine 4 (1986) 212-216.

[137] Zambrano A.J., Villava F.M., Schurig G.G., Cherwonogrodzky J.W., Preliminary results for the vaccination of pregnant cattle with Brucella abortus strain 19 or B. abortus RB51, Arch. Med. Vet. 28 (1995) 119-123.

[138] Zhan Y., Cheers C., Differential induction of macrophage-derived cytokines by live and dead intracellular bacteria in vitro, Infect. Immun. 63 (1995) 720-723. 